Electron Production and

Collective Field Generation in Intense Particle Beams

A. W. Molvik, J.-L. Vay, R. Cohen, A. Friedman,

E. Lee, J. Verboncoeur, M. Kireeff Covo

February 9, 2006 
This document was prepared as an account of work sponsored by an agency of the United States Government. Neither the United States Government nor the University of California nor any of their employees, makes any warranty, express or implied, or assumes any legal liability or responsibility for the accuracy, completeness, or usefulness of any information, apparatus, product, or process disclosed, or represents that its use would not infringe privately owned rights. Reference herein to any specific commercial product, process, or service by trade name, trademark, manufacturer, or otherwise, does not necessarily constitute or imply its endorsement, recommendation, or favoring by the United States Government or the University of California. The views and opinions of authors expressed herein do not necessarily state or reflect those of the United States Government or the University of California, and shall not be used for advertising or product endorsement purposes.

This work was performed under the auspices of the U.S. Department of Energy by University of California, Lawrence Livermore National Laboratory under Contract W-7405-Eng-48. 


\title{
Electron Production and Collective Field Generation in Intense Particle Beams [03-ERD-008 Final Report]
}

\author{
PI: LLNL \\ Art Molvik, Heavy-Ion Fusion Virtual National Laboratory (HIF- \\ VNL) \\ PIs LBNL: $\quad$ Jean-Luc Vay, Heavy-Ion Fusion Virtual National Laboratory \\ (HIF-VNL) Accelerator Modeling and Advanced Computing \\ (AMAC), Miguel Furman, Center for Beam Physics (CBP) \\ Co-investigators: $\quad$ Ron Cohen, Alex Friedman (LLNL); Ed Lee (LBNL); John \\ Verboncoeur (UCB); Michel Kireeff Covo (UCB \& LLNL)
}

\begin{abstract}
Electron cloud effects (ECEs) are increasingly recognized as important, but incompletely understood, dynamical phenomena, which can severely limit the performance of present electron colliders, the next generation of high-intensity rings, such as PEP-II upgrade, LHC, and the SNS, the SIS 100/200, or future high-intensity heavy ion accelerators such as envisioned in Heavy Ion Inertial Fusion (HIF). Deleterious effects include ion-electron instabilities, emittance growth, particle loss, increase in vacuum pressure, added heat load at the vacuum chamber walls, and interference with certain beam diagnostics.

Extrapolation of present experience to significantly higher beam intensities is uncertain given the present level of understanding.
\end{abstract}

With coordinated LDRD projects at LLNL and LBNL, we undertook a comprehensive R\&D program including experiments, theory and simulations to better understand the phenomena, establish the essential parameters, and develop mitigating mechanisms. This LDRD project laid the essential groundwork for such a program. We developed insights into the essential processes, modeled the relevant physics, and implemented these models in computational production tools that can be used for self-consistent study of the effect on ion beams. We validated the models and tools through comparison with experimental data, including data from new diagnostics that we developed as part of this work and validated on the High-Current Experiment (HCX) at LBNL. We applied these models to High-Energy Physics (HEP) and other advanced accelerators.

This project was highly successful, as evidenced by the two paragraphs above, and six paragraphs following that are taken from our 2003 proposal with minor editing that mostly consisted of changing the tense. Further benchmarks of outstanding performance are: we had 13 publications with 8 of them in refereed journals, our work was recognized by the accelerator and plasma physics communities by 8 invited papers and we have 5 additional invitations for invited papers at upcoming conferences, we attracted collaborators who had SBIR funding, we are collaborating with scientists at CERN and 
GSI Darmstadt on gas desorption physics for submission to Physical Review Letters, and another PRL on absolute measurements of electron cloud density and Phys. Rev. ST-AB on electron emission physics are also being readied for submission.

\section{PURPOSE}

Following the discovery of the photoelectron instability in 1994 at the Photon Factory $(\mathrm{PF})$ at KEK, several proton storage rings and modern electron-positron colliders have observed an instability due to a coupling between the beam and an electron cloud leading to various undesirable conditions. The ECE encompasses beam-induced multipactoring (BIM) from bunched beams, which was first observed at the PSR in 1977. BIM, being resonant in nature, is perhaps the most dramatic and damaging manifestation of the ECE.

ECE has been observed at several lepton machines such as the PEP-II and KEKB positron rings, the APS, BEPC, and CESR. Over the past several years, the phenomenon has also been observed in the high-energy proton rings PS and SPS at CERN. A highintensity instability that has been observed at the PSR for some 10 years is now recognized to be an electron-cloud effect. In these machines, the nonresonant part of the phenomenon has led to performance limitations and an intense search for mitigating mechanisms.

In Heavy Ion Inertial Fusion and Heavy-ion driven high-energy density physics (HEDP), theory and simulations suggest that electrons - arising from beam collisions with background gas and desorbed gas, and perhaps also secondary electrons from the vacuum walls - will be trapped by the beam potential and by quadrupole magnetic fields. Even a modest halo generation can cause problems due to ECE.

\section{ACTIVITIES}

We first focused on getting more insights into the electron cloud characteristics, such as time and energy scales, intensity, and spatial distribution in the presence of an ion beam. For this, we integrated the preexisting modeling tools: the code POSINST [1] developed at CBP (LBNL) for electron cloud modeling and the Particle-In-Cell code WARP [2] developed by the HIF-VNL for self-consistent modeling of beams in accelerators. We also added new physics capabilities to the codes, which we identified as needed to accomplished the proposed task: desorption, neutral dynamics and ion scattering at wall. We used this to assess approaches to a time-averaged description of the electrons, which is particularly needed and challenging for electrons in magnetic quadrupoles.

Much of the above included comparison with experimental data obtained from local experimental programs and from other sources. In particular, in the HCX experimental program we developed and implemented a set of diagnostics dedicated to the measurement of electron effects for heavy-ion fusion. These provided an opportunity to test and validate the codes. The validations that we have done increase our confidence in predictions for other HIF facilities as well as for other non-HIF applications, We are working on a joint paper with CERN and with GSI Darmstadt, to be submitted to Phys. Rev. Letters, regarding our measurements of gas emission due to ion impact on stainless 
steel surfaces (this area is critical to the success of the approved 675 M-Euro SIS-100/200 project at GSI).

This work was leveraged by the coordinated LDRD project from LBNL, as well as by SBIR funding of P. Stoltz and J. Cary (Tech-X) to implement electron cloud effect (ECE) modules in HIF codes. We have engaged active collaborations through LDRD to ensure application beyond HIF.

As part of this research effort we investigated ways in which HIF facilities may be profitably applied to study ECE in a broad range of accelerator applications. We augmented this effort by hiring a graduate student, Michel Kireeff Covo from UC Berkeley, to work on the experiments. He was subsequently awarded a SEGRF Fellowship.

\section{TECHNICAL OUTCOME}

Electron clouds and gas-pressure rise limit the performance of many major accelerator rings, and may constrain the architectures of linacs being developed as drivers for nearterm high-energy-density physics (HEDP) experiments and, in the longer-term, for heavy-ion-inertial fusion (HIF). For the last three years, we have had a multi-laboratory effort to understand the underlying physics through the coordinated application of experiment, theory, and simulation [3-16]. Our work applies a multiplicity of diagnostics and thoroughly tested simulation codes based on fundamental physics. This field is a hybrid of plasma physics and accelerator physics. This work is well regarded in the accelerator and fusion communities, as evidenced by the eight invited papers listed in the references. The space-charge potential of the positively-charged beam can electrostatically trap electrons, enabling them to accumulate. Electrons can arise from three sources: ionization of gas, beam-tube emission when impacted by ions, electrons or photons, and end-wall emission (as will be discussed). End-wall emission is not a problem, because electrostatic suppression can eliminate it; however it has proven to be a very useful tool by which to inject electrons for experimental and computational study.

At the beginning of this project, we realized that electrons could be generated from three major sources: ionization of background and desorbed gas by impact of beam ions; emission from beam tubes caused by beam-halo impact, electron impact, and photoelectrons; and emission from an end wall impacted by the beam. Initial analysis indicated that ionization of gas was likely to be the major source of electrons, so we devoted significant effort to measuring and modeling gas desorption.

We began with improving our wall interaction modeling capabilities, initially relying on subroutines developed in the code POSINST, but subsequently adding capabilities to compute gas desorption, transport, and ionization that were not in POSINST. We improved the input ability of POSINST to accept more standard variables for primary electron generation; the tracking module in a magnetic field and the electron-wall collision description were modified for greater efficiency. The structure of POSINST was also remodeled toward a higher modularity, which ease the maintenance and the 
portability of routines to other codes. The secondary electron generation module was transferred to Peter Stoltz (Tech-X) and we coordinated with him on modifications and improvements for Python wrapping. Tech-X collaborations resulted in Refs. [14-16]. The resulting Python wrapped SEY module was validated against POSINST results and made available to the WARP modules repository. Comparisons between POSINST simulations and measurements at the PSR are ongoing, particularly following beam extraction. This process is sensitive to the low-energy value of the secondary emission yield, which is important in the dissipation rate of the electron cloud. The code prediction is expected to be more reliable for this process than in steady state, hence this comparison offers a good calibration test.

We formulated a conceptual framework (Fig. 1) for self-consistently simulating electron and neutral gas effects in the WARP code [11]. We imagine this as a "roadmap" that we need to follow in order to develop our simulation tools. An updated version of the roadmap which reflects the status of the simulation capability is given here in Fig. 1. To fill in the roadmap, we developed modules to describe the various effects (which include electron generation at walls and from gas ionization, gyro-averaged drift-kinetic electron transport, and neutral gas generation and transport). This required adding modules for important effects that were not included in POSINST. We formulated options for gyroaveraged (drift-kinetic) and bounce-averaged electron movers and implemented a driftkinetic mover, as we will describe. We also designed and begun the implementation of an algorithm for efficient treatment of particles collision with complicated structures in WARP.

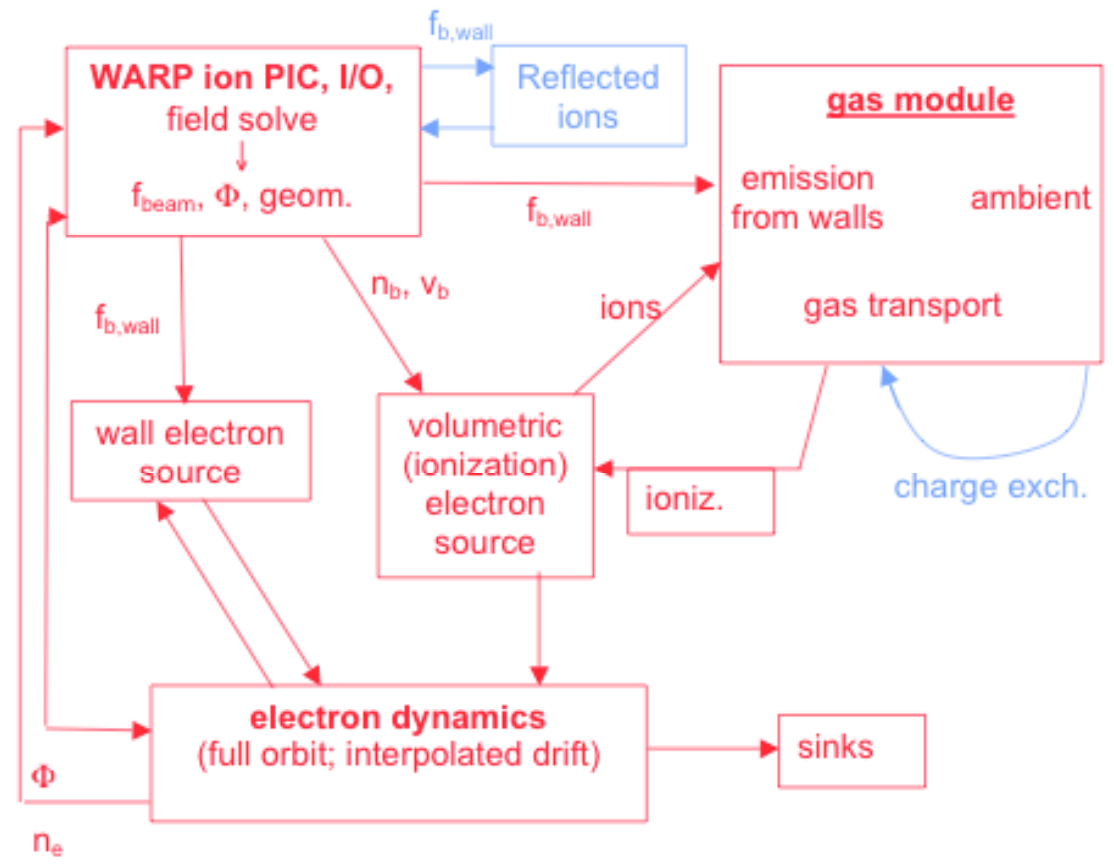

Key: operational; partially implemented $(\mathbf{5 / 6 / 0 5 )}$

Figure 1. "Roadmap" describing the different functional modules, and their interrelationships, that are ultimately needed to reach self-consistency for the modeling of HIF beams with e-cloud and gas. To date, most modules are operational. The "reflected ions" and the "charge exchange" modules are being developed. 
Before developing self-consistent descriptions of electrons in an ion beam, our initial work studied the effects of prescribed electron clouds on ion beams [3]. We ran the existing WARP in slice (XY) mode using an input deck modeling the HCX beam through 100 quadrupoles. The distribution of particles lost at the pipe wall was used to generate a distribution of secondary electrons using POSINST routines, which orbits through the quadrupoles were then followed in WARP. The result indicates that most electrons are born where the magnetic field keeps them close to walls. This underlined the importance of including ion scattering at walls in the models, since this effect eventually redistributes the loss ions to regions of the wall where the magnetic field lines pass through the beam. Orbit studies showed the effectiveness of acceleration gaps in pumping trapped electrons out of the beam. We also found using WARP that randomly varying electron densities of greater than several percent of the ion density are required to cause significant halo growth in 200 quadrupoles (Fig. 3) [3]. In general, ion beams were more robust than we had initially expected, particularly with electrons that are ionized from gas producing an electron spatial profile very similar to that of the beam. The most deleterious electron distribution was one that resonated with a breathing mode of the ion beam.

Modeling contaminating clouds of electrons requires self-consistent electron and ion simulation, including a particle advance scheme, which can follow electrons in regions where electrons are strongly magnetized, weakly magnetized, and unmagnetized.

We have developed such a mover for electrons that interpolates between full electron dynamics and drift kinetics. The algorithm builds upon the observation by Parker and Birdsall that the conventional Boris particle advance scheme, when run with time steps large compared to the cyclotron period, continues to exhibit correct drift velocities, but causes particles to gyrate with a radius that is large compared to the physical gyro-orbit, and with a frequency that is lower than the physical gyro-frequency. Our interpolation scheme corrects the former deficiency, and is thus well suited for simulating electrons everywhere in an accelerator with magnetic focusing. Specifically, the instantaneous particle velocity is advanced using the standard Boris algorithm, and then the particle positions are advanced using a blend of the instantaneous velocity and the drift velocity. With a proper choice of the interpolation parameter, a physically correct gyration radius is obtained, while also preserving correct drift and parallel (to the magnetic field) velocities [10].

This new long-time-step electron mover enables stepping of electrons on a time scale governed by the electron bounce time in the electrostatic potential well, gaining 1-2 orders of magnitude in computational speed, see Figure 2. 
$-\quad$ R. Cohen

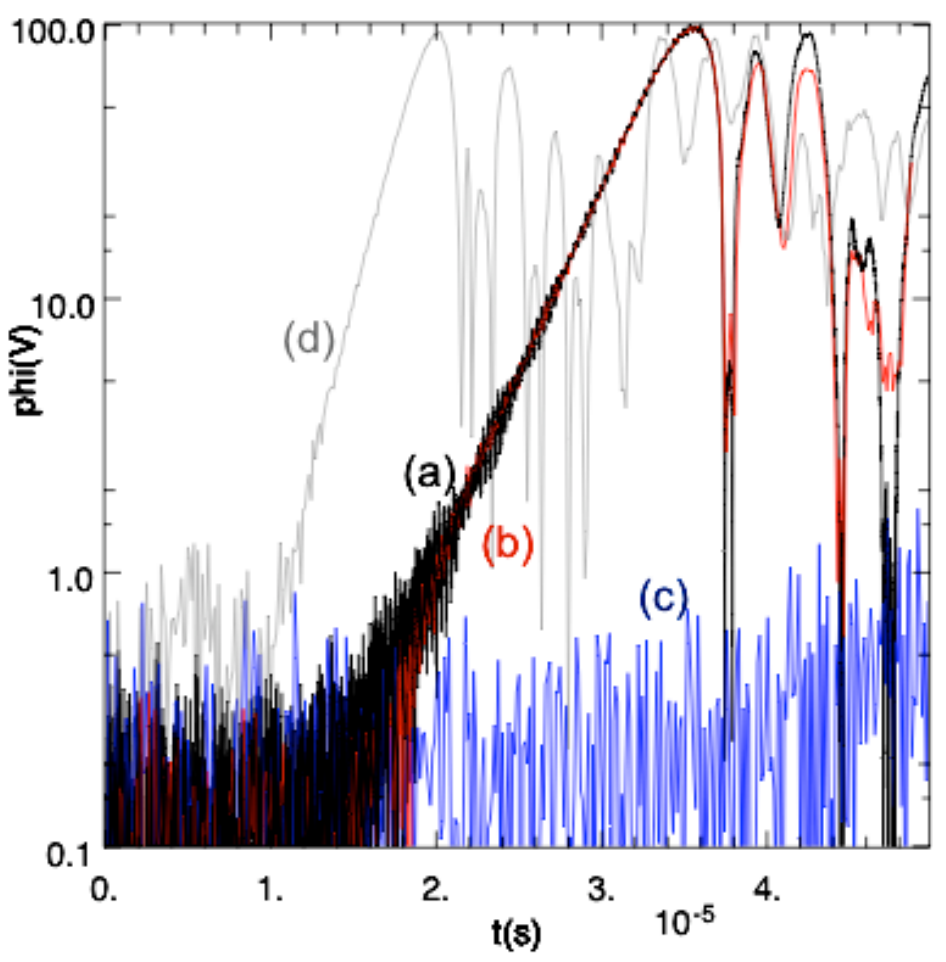

Figure 2. Test case - instability of counter-streaming thin ion beams. Shown is history of the maximum perturbed potential for (a) a simulation that resolves the gyro frequency; (b) the interpolated mover with 20 times larger timestep; (c) standard Boris mover with the larger timestep; (d) interpolated mover with beams twice as wide.

We study electron cloud effects in the High-Current Experiment (HCX), shown in Fig. 3. A suppressor ring electrode, surrounding the beam after it exits the last quadrupole magnet, can be biased to $-10 \mathrm{kV}$ to prevent ion-induced electron emission off an end wall (a slit plate) from reaching the magnets, or can be left unbiased to allow electrons to be emitted from the end wall and to flow into the magnets. For some of the work described here, we have replaced the cylindrical suppressor ring with two bars, one above and one below the beam. Simulations show that these suppress electron emission from the end wall, as well the suppressor ring did, when both bars are biased to $-10 \mathrm{kV}$. However, as will be discussed, a new mode of operation is now possible where simulations predict that all electrons emitted from the end wall will be collected by a positively biased suppressor bar.

In order to calibrate diagnostics and simulations, we measured gas desorption and electron emission from $1 \mathrm{MeV} \mathrm{K}{ }^{+}$ions striking stainless steel at angles near grazing incidence $[4,5]$. This work led to basic physics studies of gas desorption scaling with ion energy, showing that the desorption scales with the electronic component of ion slowing in matter $(\mathrm{dE} / \mathrm{dx})^{\mathrm{n}}$ where $1 \leq \mathrm{n} \leq 2$ [17]. A similar study of electron emission from ion 


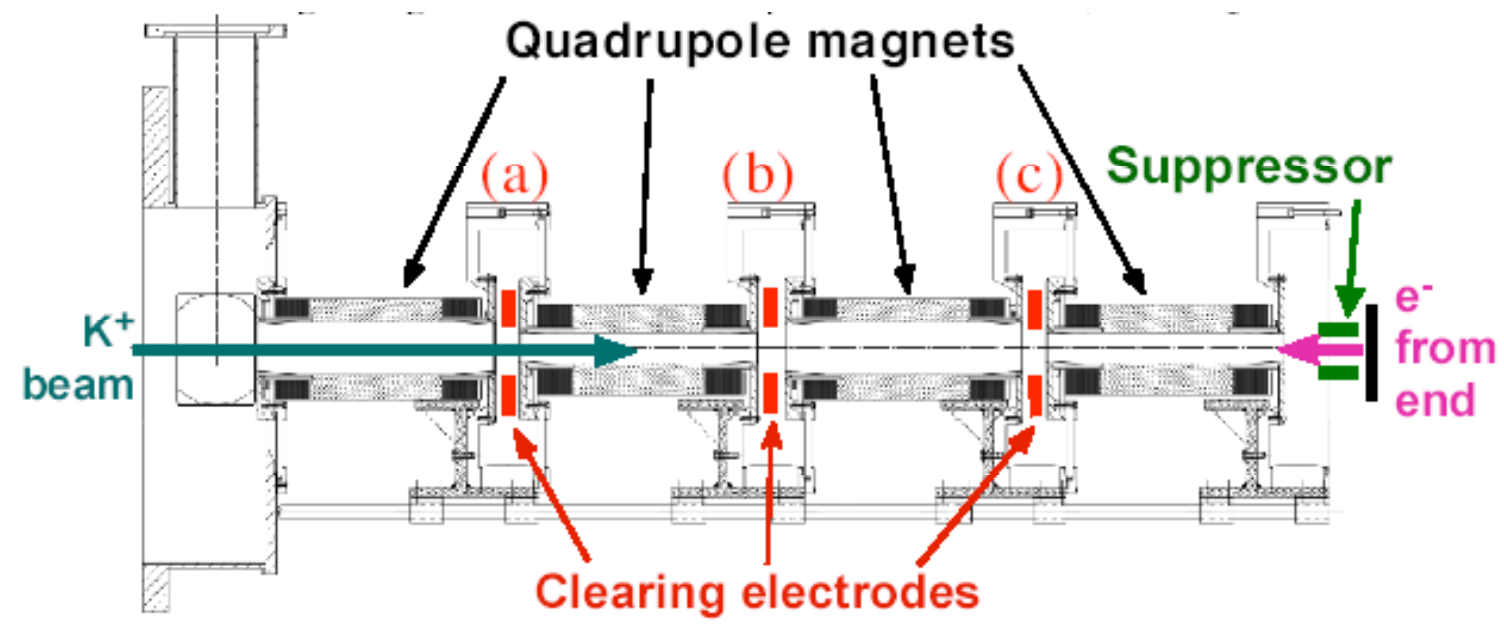

Fig. 3. Magnetic quadrupole region of HCX, from the D2 diagnostic region on the left to the D-End diagnostic region beginning on the right. The lattice half-period is $0.52 \mathrm{~m}$. Clearing electrodes a, b, and c are in the drift regions between each pair of quadrupoles. A suppressor electrode prevents beam-induced electron emission, from structures hit by beam in D-End, from reaching the quadrupole magnets. Vacuum pumps are located between each magnet, as well as at both ends of the region shown (base pressure: $1 \times 10^{-7}$ Torr $<\mathrm{P}<3.5 \times 10^{-7}$ Torr). Gas can be fed at tank $\mathrm{b}$. The cylindrical suppressor ring has been replaced with 2 separately biased plates that can perform additional functions.

impact showed a linear scaling with the electronic component of $\mathrm{dE} / \mathrm{dx}[13,18]$. Related previous work includes studies of high-fill factor transport in electrostatic quadrupoles [19].

\section{Gas desorption studies}

Heavy-ion beams impinging on surfaces near grazing incidence (to simulate the loss of halo ions) generate copious amounts of electrons and gas that can degrade the beam. We measure $\sim 100$ electrons and $\sim 10,000$ gas molecules, emitted for each $1 \mathrm{MeV} \mathrm{K}^{+}$incident on stainless steel, as shown in Fig. 4 [5]. Electron emission scales as $1 / \cos (\theta)$, where $\theta$ is the ion angle of incidence relative to normal. If we were to roughen a surface by blasting it with glass beads, then ions that were near grazing incidence $\left(90^{\circ}\right)$ on smooth surface would strike the rims of the micro-craters at angles closer to normal incidence. As expected, this reduced the electron emission: the factor of 10 reduction in Fig. 4(a), implies an average angle of incidence of $62^{\circ}$. Gas desorption, which varies more slowly with $\theta$ (Fig. 4(b)), decreased a factor of $\sim 2$, and along with the electron emission became independent of the angle of incidence on a rough surface. 

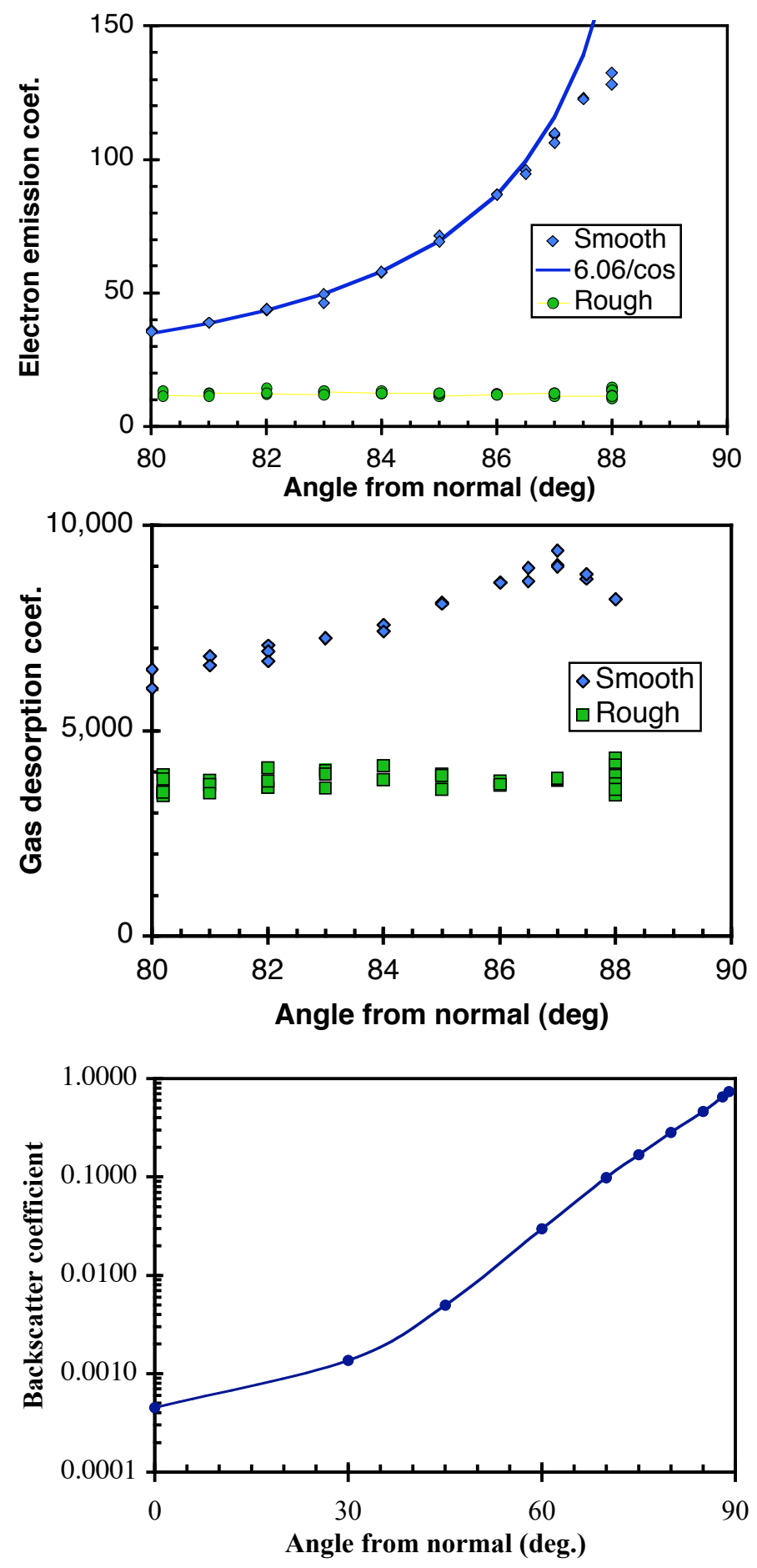

Fig. 4. (a) Electron emission coefficient, (b) Gas desorption coefficient, (c) Ion backscatter from a smooth surface, as predicted by the SRIM code.

In a quadrupole magnet, electrons emitted by lost primary ions are trapped near the wall by the magnetic field, but grazing incidence ions can backscatter and strike the wall again at an azimuth where magnetic field lines intercept the beam. These generate electrons throughout the beam. The SRIM Monte Carlo code [23] predicts that $\sim 75 \%$ of $1 \mathrm{MeV} \mathrm{K}^{+}$ 
ions backscatter when incident at $88-89^{\circ}$ from normal on a smooth surface. Most scattered ions are within $\sim 10^{\circ}$ of the initial direction but a few scatter to $\sim 90^{\circ}$. Ion scattering decreases rapidly away from grazing incidence, Fig. 4(c). At 62 deg. the predicted ion backscattering (from a rough surface) is $3 \%$, down a factor of 25 from the peak, which should significantly reduce electrons in the beam from lost halo ions.

Copious gas desorption can result from ions striking beam tubes in accelerators. The desorption is much larger from heavy ions than from protons, in fact, pressure rises limit or threaten to limit the beam current in a number of heavy-ion accelerators [20]. Large desorption coefficients (number of molecules desorbed by each ion) of $\leq 20,000$ were measured at CERN for $800 \mathrm{MeV}$ lead ions (4.2 MeV/u where $\mathrm{u} \equiv$ nucleon mass) [21] and $\leq 37,000$ for $158 \mathrm{GeV} / \mathrm{u}$ indium ions [22] impinging on stainless steel targets that were chemically cleaned and baked-in-situ in ultra-high vacuum chambers. Similar values, $\leq 15,000$, are measured for $1 \mathrm{MeV}$ potassium ions incident on chemically cleaned (but not baked) stainless steel in a high-vacuum chamber [5].

Attempts to model the desorption as sputtering, with the SRIM code [23], predicted 1-2 orders of magnitude lower values than measured. (SRIM is a Monte Carlo code that computes the transport of ions in matter.) Schenkel [24] suggested an alternative mechanism: that desorption by energetic ions is due to electronic sputtering, rather than to the conventional sputtering (sometimes called physical sputtering) that SRIM computes. In this paper we test, and verify, Schenkel's hypothesis.

We define desorption as removal of volatile gas from a surface or near-surface region. Sputtering includes this as well as the removal of non-volatile material. Physical and electronic sputtering dominate in different ion energy ranges. Very low energy ions (e.g., $\leq 4 \mathrm{keV}$ oxygen ions [25]) lose energy in matter primarily through nuclear scattering, Fig. 1 , which is responsible for physical sputtering. Higher energy ions lose energy in matter primarily to electrons. Such energetic ions, incident on frozen gases or other insulators, have been shown to produce copious sputtering that scales with the electronic component of ion slowing in matter $\left(\mathrm{dE}_{\mathrm{e}} / \mathrm{dx}\right)$ to a power of 1 to several and has been termed electronic sputtering [25]. We believe that the experiments described here are the first to look for electronic sputtering of volatile gas from nominally clean metals. Compared with previous studies of electronic sputtering from insulators, with metals we observe similar scalings of desorption with $\mathrm{dE}_{\mathrm{e}} / \mathrm{dx}$, but observe much less variation with the ion angle of incidence.

To test the hypothesis that these copious gas desorption coefficients were caused by electronic sputtering [24], we identified two energy ranges for study: (1) A high-energy range above the peak of the electronic $\mathrm{dE}_{\mathrm{e}} / \mathrm{dx}$, where $\mathrm{dE}_{\mathrm{e}} / \mathrm{dx}$ decreases with increasing energy. This range is available to collaborators with the SIS18 at GSI Darmstadt [26]. (2) A low-energy range (70 to $1000 \mathrm{keV}$ ) with $\mathrm{K}^{+}$ions for which nuclear slowing dominates below and electronic slowing dominates above $250 \mathrm{keV}$, as shown in Fig. 5. Here the electronic and nuclear components of ion slowing have opposite slopes. The low-energy range was available in our program: the Heavy-Ion Fusion Science Virtual National Laboratory (HIFS-VNL). The STS-500 Ion Source Test Stand [27] in the HIFS-VNL at 
LLNL accelerated $\mathrm{K}^{+}$ions to energies of 50 to $500 \mathrm{keV}$. The HCX in the HIFS-VNL at LBNL accelerates $\mathrm{K}^{+}$ions to $\sim 1000 \mathrm{keV}[5,19]$.

The experimental details are described elsewhere [5,21]. Briefly, we determine desorption coefficients by measuring the pressure rise, $\Delta \mathrm{P}($ torr), in a known volume, $\mathrm{V}$, from which we calculate the number of desorbed molecules. A Faraday cup for the lowenergy range, or a current transformer for the high-energy range, measures the beam current transmitted through the entrance aperture, which we integrate to determine the total number of ions, $\mathrm{N}_{\mathrm{b}}$ into the volume and incident on a stainless steel target. For the low-energy range, the entrance aperture has been reduced from the $3 \times 25 \mathrm{~mm}$ of Ref. [5], to $1 \times 20 \mathrm{~mm}$ for the $70-400 \mathrm{keV}$ data from the STS-500 heavy-ion beam source test stand [27]. We obtain the gas desorption coefficient $\gamma_{0}$, defined as the number of volatile molecules desorbed per ion incident:

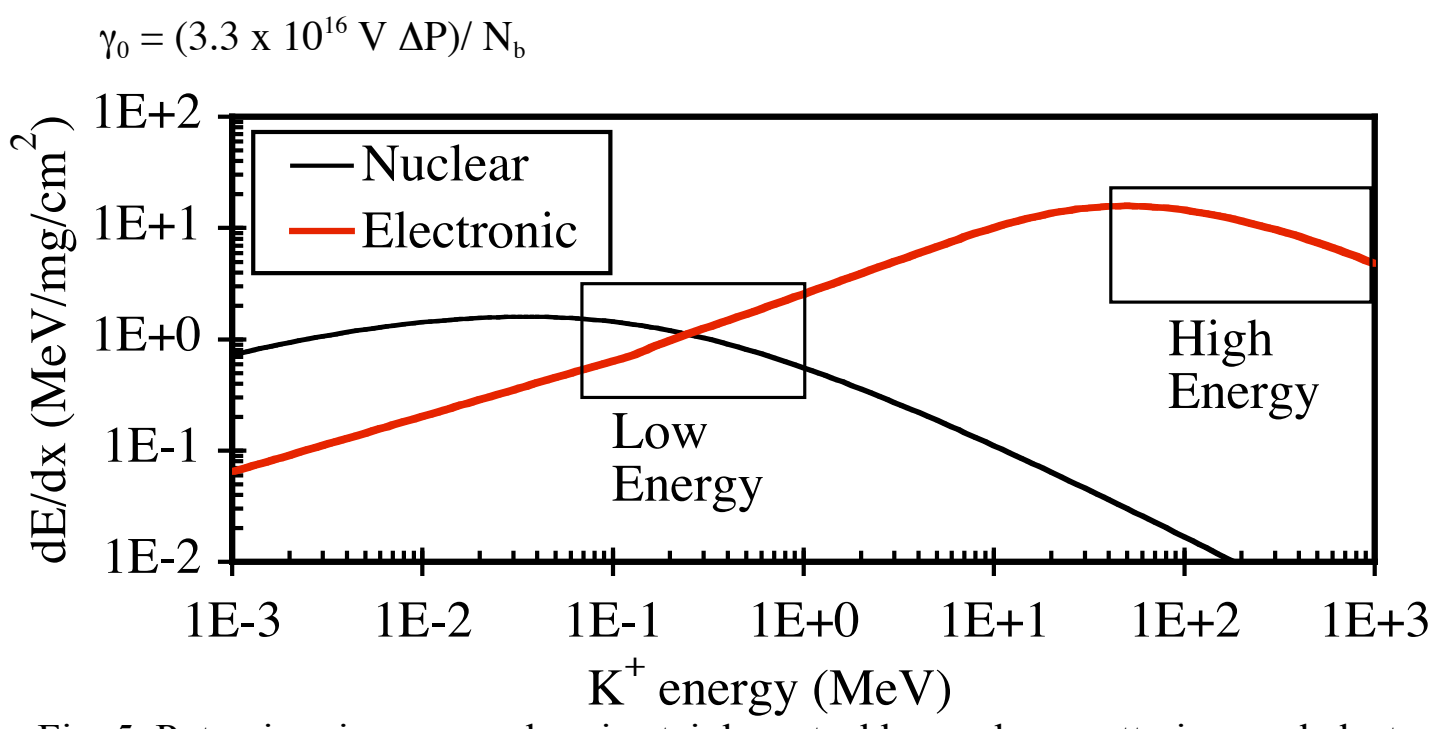

Fig. 5. Potassium ion energy loss in stainless steel by nuclear scattering, and electronic slowing.

We select data from a narrow range of angles of incidence (84.0-85.5 ) for low-energy range ions, over which gas desorption is nearly constant, and plot the average versus the beam energy in Fig. 6(a). (Selection of different angles would not significantly change the slope or magnitude of the plot in Fig. 6(a).) Desorption coefficients are scaled for ease of comparing slopes with the electronic, nuclear, and total components of ion slowing. Error bars $( \pm 250 / 10 \mathrm{k})$ are computed from random variations in the pressure rise, ion beam current, and duration and have similar magnitude at all ion energies. It is apparent that desorption coefficients increase with energy as does the electronic stopping, that they have a trend opposite to that of nuclear scattering, and they are not nearly constant like the total $\mathrm{dE} / \mathrm{dx}$. The same data are plotted versus electronic slowing in Fig. 7 , where the slope on the log-log plot indicates the power of the scaling with $\mathrm{dE}_{\mathrm{e}} / \mathrm{dx}$. For $\mathrm{K}^{+}$data, a slope of 2 at lower $\mathrm{dE}_{\mathrm{e}} / \mathrm{dx}$ and of 1 at intermediate $\mathrm{dE}_{\mathrm{e}} / \mathrm{dx}$ is a good fit. Similar dependencies with $\mathrm{dE}_{\mathrm{e}} / \mathrm{dx}$ have been observed for electronic sputtering from ions incident on frozen gases [25]. 
In the high-energy range, above the peak $\mathrm{dE}_{\mathrm{e}} / \mathrm{dx}$, desorption should decrease, as shown in Fig. $6 \mathrm{~b}$ if it scales with the electronic component of $\mathrm{dE} / \mathrm{dx}$. The plot of desorption versus $\mathrm{dE}_{\mathrm{e}} / \mathrm{dx}$ for $15-100 \mathrm{MeV} / \mathrm{u}$ uranium ions $\left(\mathrm{U}^{73+}\right)$ at normal incidence on stainless steel, measured at GSI Darmstadt and shown in Fig. 7, scales approximately with $\left(\mathrm{dE}_{\mathrm{e}} / \mathrm{dx}\right)^{2}$.
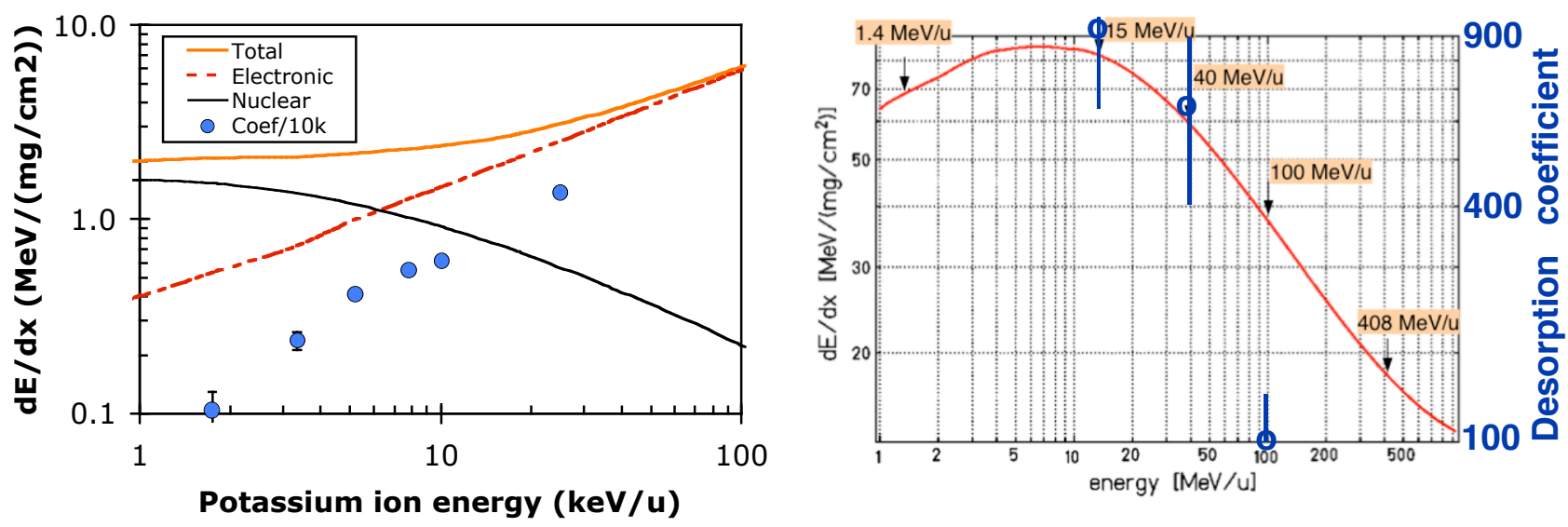

Figure 6 (a) Potassium ion stopping and slowing in stainless steel by: nuclear scattering, electronic slowing, the sum of these (gold - upper solid line) and desorption coefficients (blue points - multiplied by $10^{-4}$ to plot on the same scale for ease in comparing slopes) for ions at the angles of 84.0-85.5 ${ }^{\circ}$ from normal to target. (b) Similar data for uranium ions at normal incidence at the SIS18 at GSI, Darmstadt, Germany.

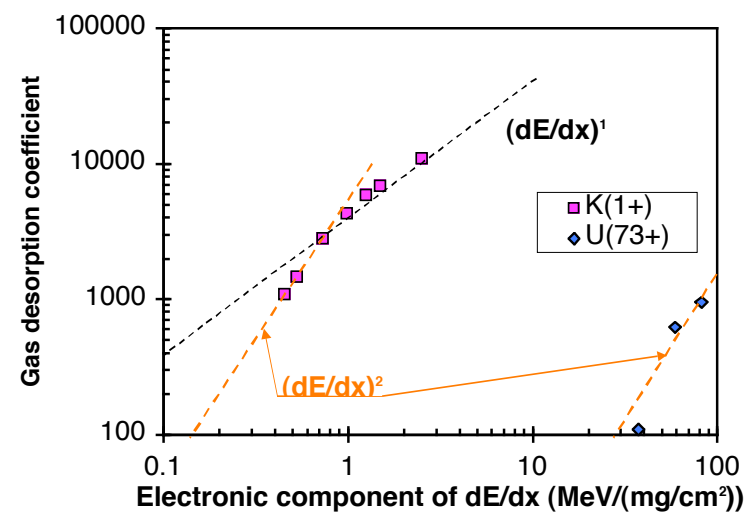

Figure 7. Gas desorption coefficients plotted as a function of the electronic component of $\mathrm{dE}_{\mathrm{e}} / \mathrm{dx}$. Data for potassium ions between 70 and $1000 \mathrm{keV}$ (red square points). Gas desorption from uranium ion impact (blue diamonds) also increases with $(\mathrm{dE} / \mathrm{dx})^{2}$, where desorption and $\mathrm{dE} / \mathrm{dx}$ are both decreasing as the ion energy increases.

Desorption from energetic ions striking metals has effects in multiple fields. It limits accelerator performance, and impacts magnetic fusion and astrophysics.

Limiting the beam current in accelerators by pressure rise, limits the production rate of quark-gluon plasma events in the Relativistic Heavy-Ion Collider (RHIC) or in the Large Hadron Collider (LHC) with heavy-ion beams. Pressure rise also threatens accelerator 
driven studies of warm dense matter (WDM), high energy density physics (HEDP) [2830], and could limit cost-reductions in future heavy-ion accelerators for driving inertial fusion energy power plants [31,32].

In magnetic-fusion tokamaks, wall desorption (recycling) is normally dominated by physical and chemical sputtering from low energy ion bombardment [33], however some instabilities carry energetic ions to the wall [34], resulting in the more copious electronic sputtering.

In astrophysics, cosmic ray sputtering of gas condensed on dust surfaces may affect gas densities in nebulae. In addition, modeling shows how the dominant, and normally nonreactive, $\mathrm{H}_{2}$ and $\mathrm{CO}$ may form $\mathrm{CH}_{4}$ and other prebiotic molecules [35], as are observed in the Orion nebula [36]. Finally, electronic sputtering transports not only fragments but also intact complex molecules including bio-molecules [37].

The dependence on $\mathrm{dE}_{\mathrm{e}} / \mathrm{dx}$, which we observe, is similar to earlier experimental and computational studies of electronic sputtering of insulators that scaled with powers of 1 for noble to 2 for molecular frozen gases [25]. For these, molecular gas desorption scaled with $\mathrm{dE}_{\mathrm{e}} / \mathrm{dx}$ to a power of 2 at low temperatures $(\leq 20 \mathrm{~K})$ [25], however $\mathrm{H}_{2} \mathrm{O}$ desorption became linear at higher temperature [38].

In summary, we discovered that desorption by energetic heavy ions scales with the electronic component of ion slowing in matter, therefore it can be classified as electronic sputtering and it is much larger for heavy ions than for protons. Our results for ions incident on metals show a scaling of desorption with the first to second power of electronic energy loss, similar to that seen for ions incident on frozen gases.

The identification of electronic sputtering as the mechanism for gas desorption from metals by energetic heavy ions is a significant step towards understanding ion-induced desorption in accelerators and astrophysics, and more effective mitigation in accelerators. A manuscript reporting this work is being prepared, together with collaborators at CERN and GSI-Darmstadt, for submission to Physical Review Letters [17].

\section{Other gas related studies}

We have developed a gridded ion-collector (GIC) diagnostic that measures the timedependent gas density in a quadrupole magnet and within the beam [9]. A gas molecule has a $\sim 1 \%$ probability of being ionized by the High Current Experiment (HCX) $1 \mathrm{MeV}$, $0.18 \mathrm{~A}, \mathrm{~K}^{+}$ion beam. The resulting cold ions are expelled radially across the quadrupole magnetic field $\left(\mathrm{B}^{\prime} \sim 8 \mathrm{~T} / \mathrm{m}\right.$ ) by the $2 \mathrm{kV}$ beam potential. The ions are expelled in $\sim 0.5 \mu \mathrm{s}$ after ionization, providing a time-dependent current collected by the GIC during the $5 \mu \mathrm{s}$ beam duration.

The GICs are located on the minor axis of the octagonal diagnostics beam-tube, Fig. 8, where the quadrupole magnetic field is tangent to the electrode surface, which suppresses electron emission or collection by the electrodes. A GIC diagnostic consists a collector that is shielded from the beam potential by a pair of grounded grids. Without the grids, 
the capacitive signal at the beam head and tail would exceed the expelled ion current by a factor of $\sim 500$. We tested the GIC by injecting argon gas, which increased the density by up to an order of magnitude above the base density, measured with an ion gauge. As shown in Fig. 9, the measured current increased linearly with gas density, demonstrating that the GIC measures gas density within a quadrupole magnet. These data also enable determination of fractional neutralization of the beam by ionization of gas, and will constrain simulations.

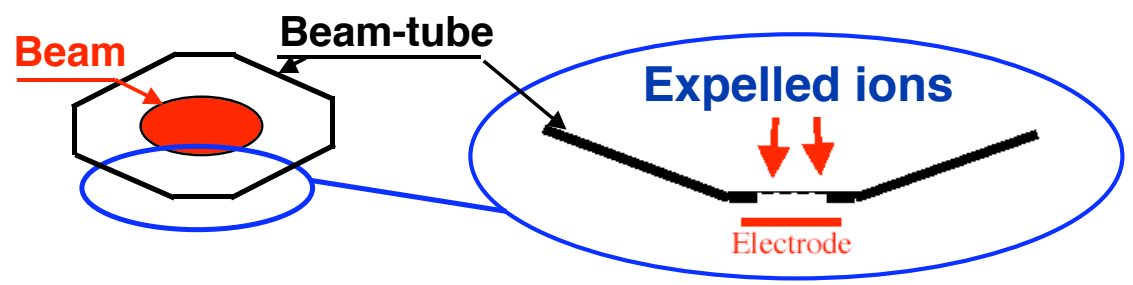

Fig. 8. Diagnostics are mounted on an octagonal tube, that fits within an elliptical quadrupole magnet tube. The Gridded-ion-collector (GIC) is shown.

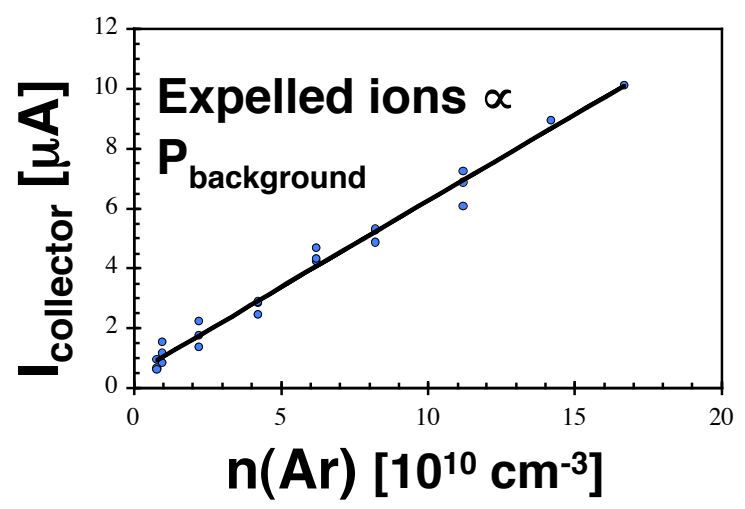

Fig. 9. The expelled ion current increases linearly with the background pressure, indicating that it provides a measurement of gas density within a magnetic quadrupole.

We have developed a method to measure the velocity of desorbed gas: after a molecule has been desorbed, it can be excited by a subsequent collision with an energetic beam ion. We photograph the region in front of a target from the side, using a fast gated camera, as shown in Fig. 10. By gating the camera $0.5 \mu$ s later on each shot shown in Fig. 11 , we can observe the gas expanding away from the target. Lineouts from Figure 11 are plotted vertically and displaced horizontally in a pseudo-streak-camera presentation. Gas velocity is proportional to the slope of the contours. 

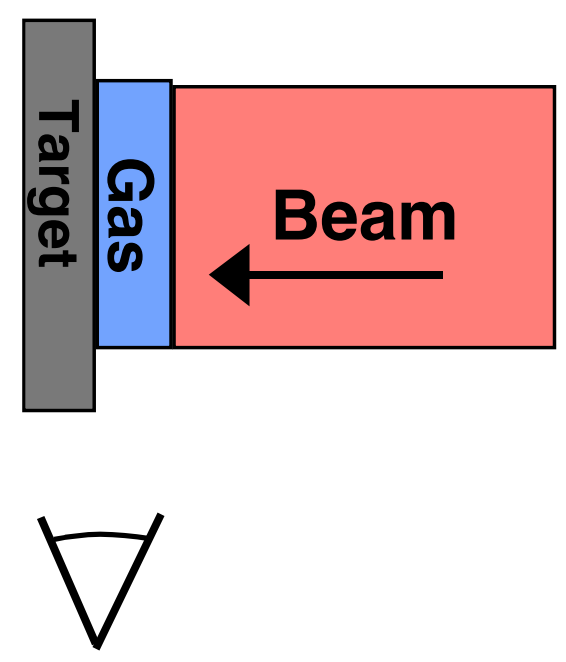

Figure 10. A planar target is viewed from the side. Beam ions strike the target desorbing gas. Subsequent beam ions can excite the gas, resulting in light emission, that we photograph with a gated camera.

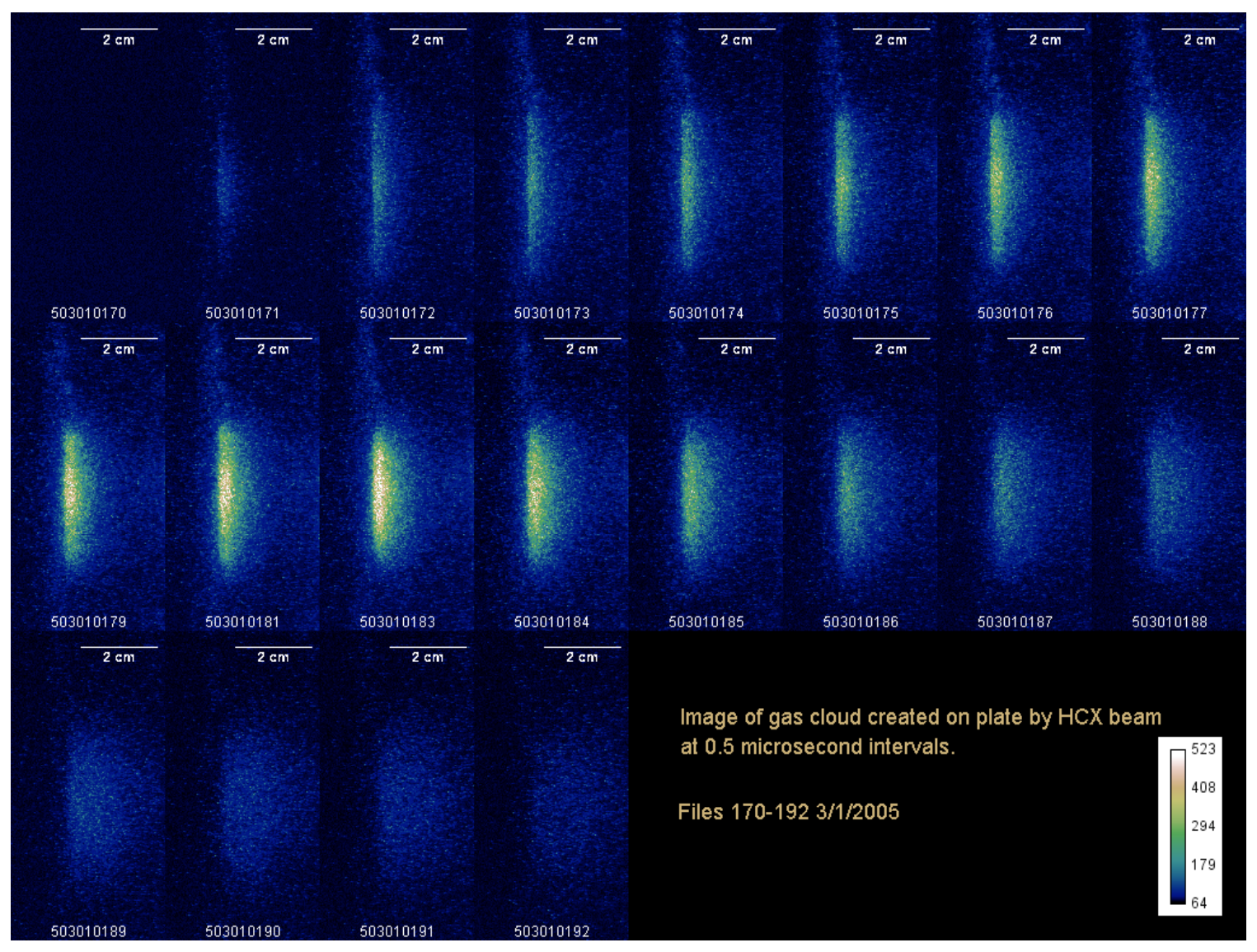

Figure 11. Images of the gas cloud show growth and decay as a function of time. 


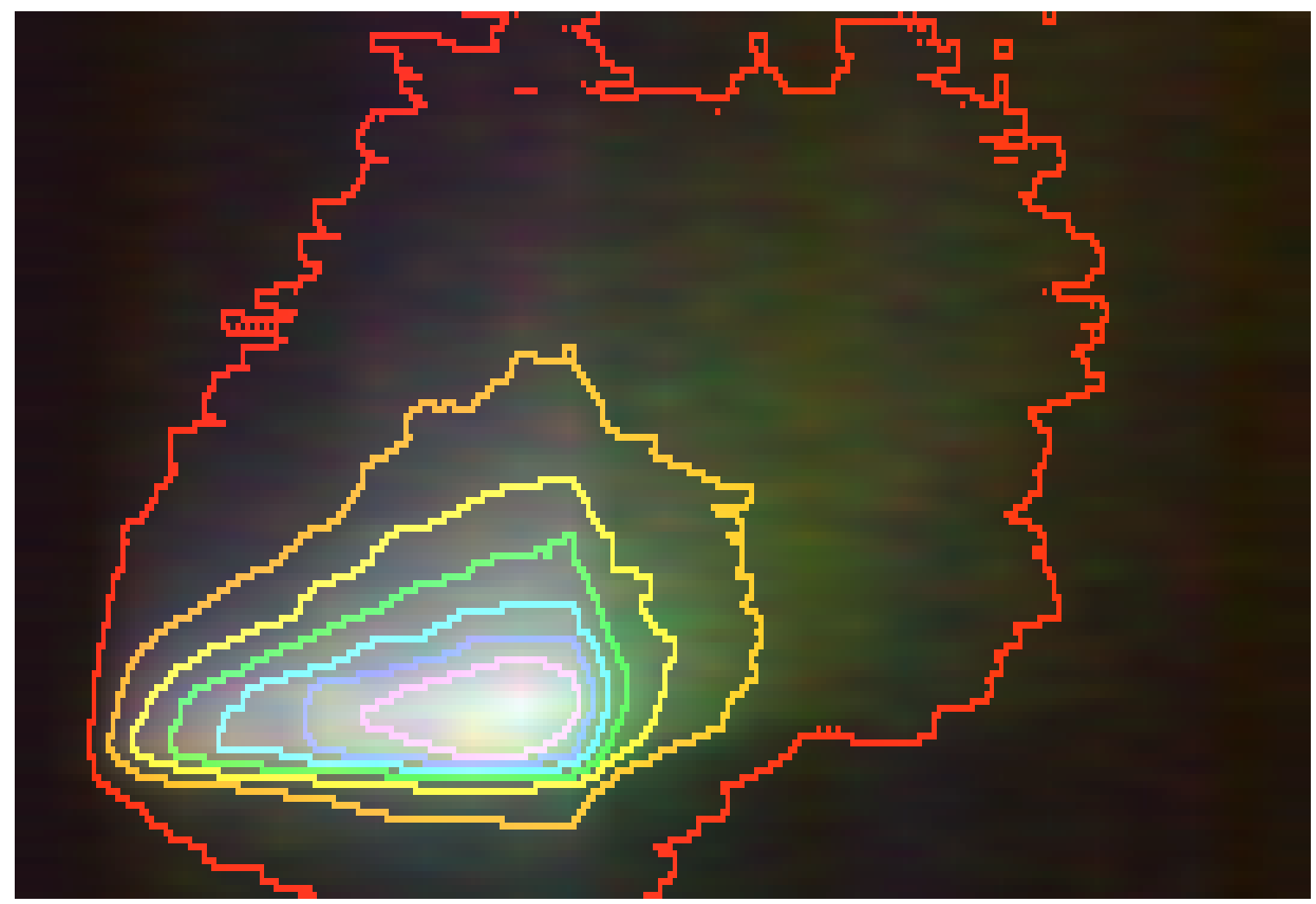

Figure 12. Lineouts from Figure 11 are plotted vertically and displaced horizontally in a pseudo-streak-camera presentation. Gas velocity is proportional to the slope, the green contour corresponds to a velocity of $1 \mathrm{~mm} / \mu \mathrm{s}$, the maximum slope corresponds to nearly $4 \mathrm{~mm} / \mu \mathrm{s}$.

We have constructed a gridded retarding potential analyzer (RPA), similar to the GIC shown in Fig. 8, but with multiple grids that enable it to measure either ion or electron total currents and energy distributions. The total ion current (ions of all energies) that is expelled by the positive $2000 \mathrm{~V}$ space-charge potential of the beam is proportional to the

Ionization by $1 \mathrm{MeV} \mathrm{K}+$

\begin{tabular}{|l|r|r|}
\hline & Average & \multicolumn{1}{|l|}{ STDEV } \\
\hline $\mathrm{H} 2 \mathrm{O}$ & $1.43 \mathrm{E}-16$ & $6.28 \mathrm{E}-18$ \\
$\mathrm{~N} 2$ & $3.30 \mathrm{E}-16$ & $2.10 \mathrm{E}-17$ \\
$\mathrm{Ar}$ & $3.56 \mathrm{E}-16$ & $4.17 \mathrm{E}-18$ \\
$\mathrm{He}$ & $6.28 \mathrm{E}-17$ & $4.27 \mathrm{E}-18$ \\
$\mathrm{CO} 2$ & $3.57 \mathrm{E}-16$ & $2.10 \mathrm{E}-17$ \\
$\mathrm{Ne}$ & $1.50 \mathrm{E}-16$ & $8.42 \mathrm{E}-18$ \\
$\mathrm{H} 2$ & $8.73 \mathrm{E}-17$ & $2.51 \mathrm{E}-18$ \\
\hline
\end{tabular}

Charge exchange of $1 \mathrm{MeV} \mathrm{K+}$

$\mathrm{N} 2$ $1.30 \mathrm{E}-16$

Ar $\quad 9.80 \mathrm{E}-17$

Table 1. Cross sections for ionization plus charge exchange of selected gases by a $1 \mathrm{MeV}$ potassium ion beam. 
product of the beam current times the gas density. By injecting a selected gas, measuring its pressure with a calibrated vacuum gauge, and knowing the beam current, one can determine the cross-section for ionization (plus charge exchange) of that gas species by the beam [39].

\section{Beam tube emission}

Beam tube emission is one of the major sources of electrons, in most high-energy physics accelerators it is the dominant source. Electron emission from beam tubes could be caused by beam-halo impact, electron impact, and photoelectrons. With the large emission coefficients observed for heavy ions impinging a surface near grazing incidence, Fig. 4(a), we expected this to be the dominant driver for emission from beam tubes in our experiments.

Inorder to increase our understanding of the mechanism of ion-stimulated electron production near grazing incidence, we acquired data with the Gas-Electron Source Diagnostics experiment (GESD), using the STS 500 Facility with $\mathrm{K}+$ ions hitting a stainless steel target. The energy ranged from $50 \mathrm{KeV}$ to $400 \mathrm{KeV}$, where nuclear stopping power transitions to electronic stopping power predominance, as shown in Fig. 5. We found that the emission coefficient scaled linearly with the electronic component of ion slowing in matter $\left(\mathrm{dE}_{\mathrm{e}} / \mathrm{dx}\right)$. We modeled this process, computing $\mathrm{dE}_{\mathrm{e}} / \mathrm{dx}$ at $0.1 \mathrm{~nm}$ intervals from 0 to $2 \mathrm{~nm}$ using the SRIM code. This enabled us to include the effect of ions stripping to higher charge states within a few atomic layers of the surface, which increases $\mathrm{dE}_{\mathrm{e}} / \mathrm{dx}$ and can reduce the dependence of emission on angle of incidence from the $1 / \cos (\theta)$ seen at $1 \mathrm{MeV}$ and higher energies to the dependence computed in Fig. 13(a) which is similar to that measured, Fig. 13(b). A manuscript describing this work has been prepared for submission to Physical Review Special Topics - Accelerators and Beams [39].

Electron clearing electrodes are inserted in the drift regions between quadrupole magnets, as shown in Figure 4, and can be biased to $+10 \mathrm{kV}$ to remove electrons from the drift regions between magnets. A ring electrode surrounding the beam between the exit of the last quadrupole magnet and the downstream diagnostics can be biased to $-10 \mathrm{kV}$ to suppress electrons off the end structures from reaching the magnets.

Each clearing electrode has an inner diameter of $8 \mathrm{~cm}$ and a minor diameter of $1.3 \mathrm{~cm}$, which places the electrodes about $1 \mathrm{~cm}$ outside of the magnet bore such that beam halo ions do not strike the electrodes. The capacitive electrode is $28 \mathrm{~cm}$ long, surrounding thebeam and nearly flush to the $3 \times 5 \mathrm{~cm}$ radius magnet bore (It is installed only when the diagnostics on an octagonal tube are not installed). A suppressor ring, that is $10 \mathrm{~cm}$ diameter and $10 \mathrm{~cm}$ long, surrounds the beam after it exits the last magnet. It can be biased to $-10 \mathrm{kV}$ to prevent electrons that are created by beam impinging on metal surfaces from being transported back into the quadrupole magnets. For these 

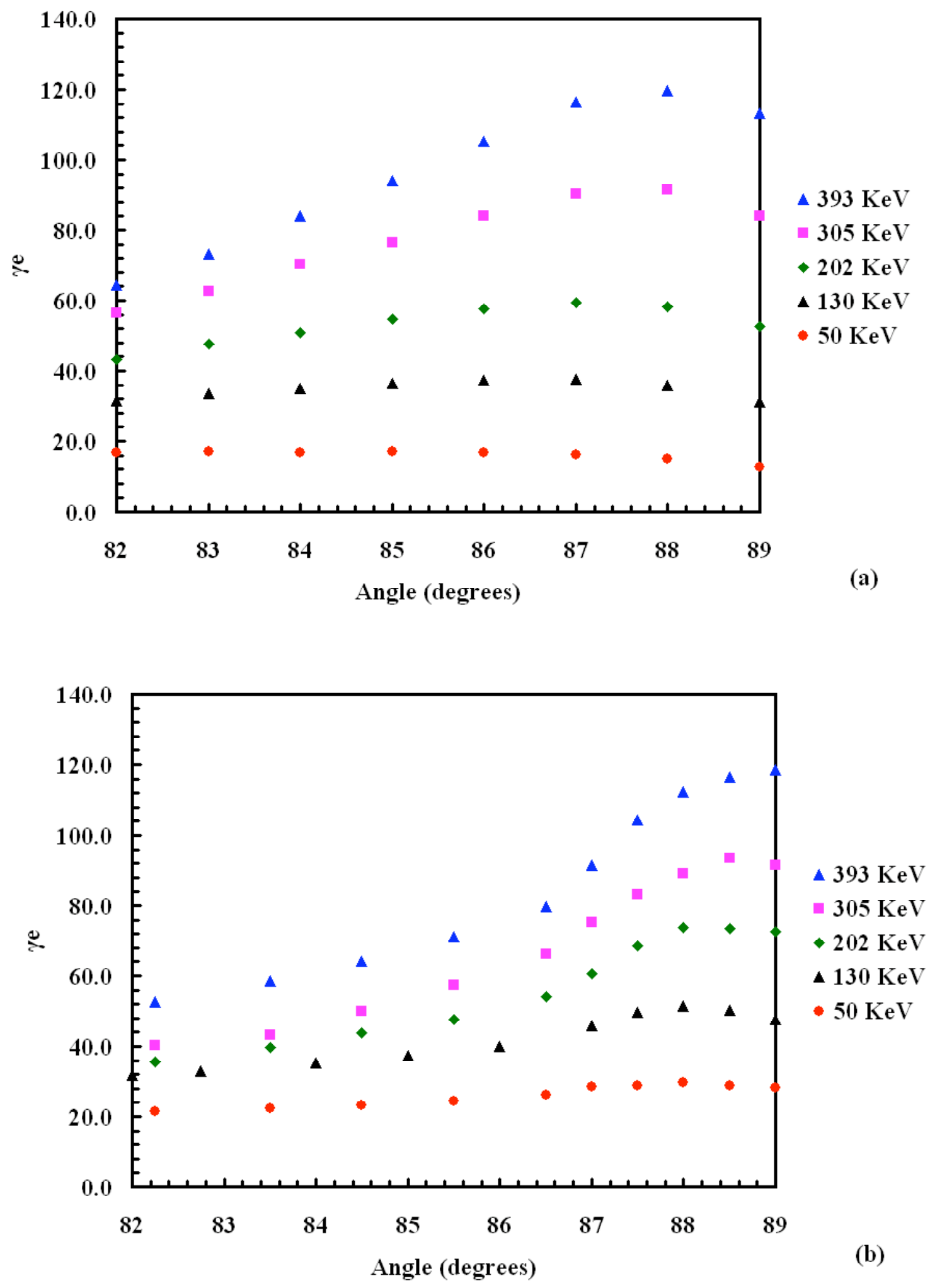

Figure 13. Ion-induced Electron Emission. (a) Theoretical $\Gamma_{e}$ for $\mathrm{K}^{+}$ions with different energies hitting stainless steel target. (b) Experimental $\Gamma_{e}$ for $\mathrm{K}^{+}$ions with different energies hitting stainless steel target obtained using GESD at STS-500. 


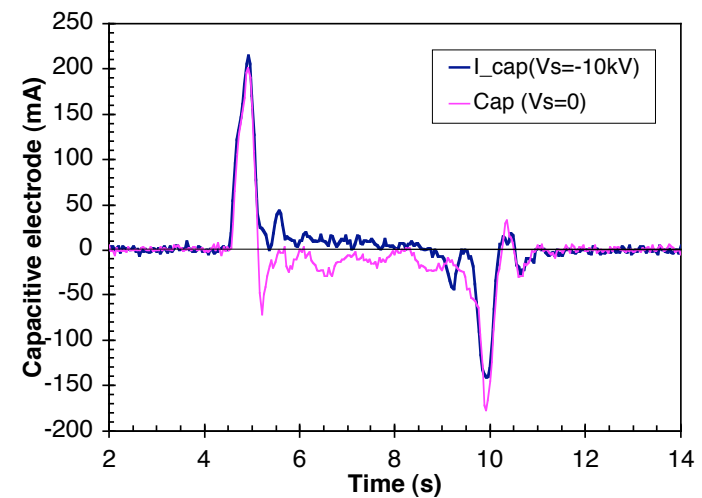

$\mathrm{a}$

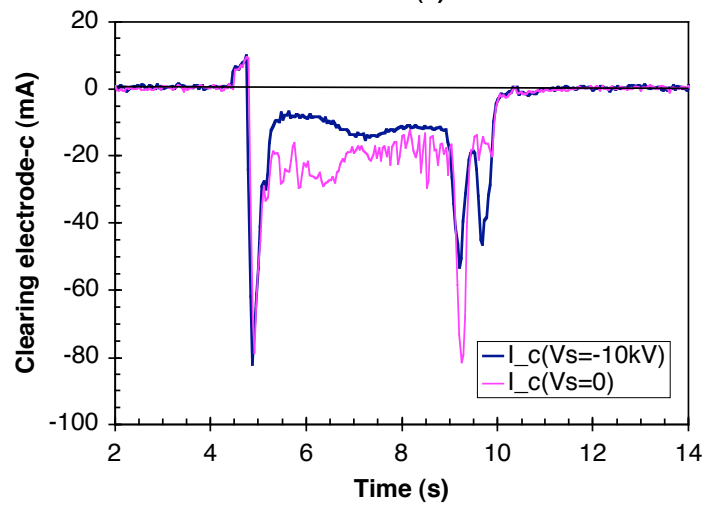

b

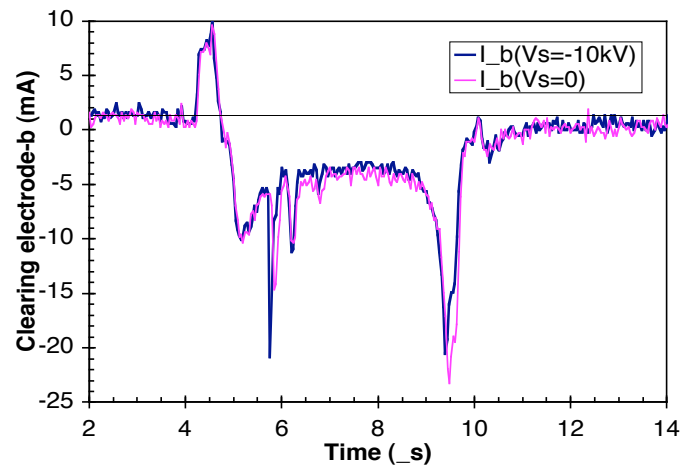

C

Figure 14. Currents to (a) a capacitive electrode in magnet 4 , (b) clearing electrode-c between magnets 3 and 4, (c) clearing electrode-b between magnets 2 and 3, and (d) clearing electrode-a between magnets 1 and 2 (See Fig. 3 for locations).

experiments, the front plate of a slit scanner is inserted, providing a grounded metal surface on which the ion beam impinges, generating $\geq 6$ electrons per incident ion [5,9]. It is located about $30 \mathrm{~cm}$ from where the field of the last quadrupole magnet ends.

The currents to a capacitive electrode in the fourth magnet and to each of three clearing electrode are shown in Fig. 14 with the suppressor electrode biased to 0 and $-10 \mathrm{kV}$, The capacitive electrode shows the expected positive value during the beam head and 
negative value during the tail, Fig. 14(a). During the nearly flat portion of the beam pulse, the capacitive current is positive with the suppressor biased to $-10 \mathrm{kV}$, consistent with electron emission from the electrode. This is also consistent with the finite electron current to the clearing electrodes, even when the suppressor is biased to prevent end-wall emission from reaching the magnets, Fig. 14(b,c). This could come either from beamtube emission or from ionization of gas, tests of which will be discussed later.

For a suppressor bias of $0 \mathrm{kV}$, the current to the capacitive electrode is mostly negative, indicating that electrons are flowing into the electrode to a greater degree than they are being emitted. These measurements are consistent with the suppressor functioning as intended: it prevents electrons generated downstream from reaching the quadrupole magnets, therefore fewer electrons are available to flow into the capacitive electrode, and the beam potential enhances the flow of electrons that are emitted from the capacitive electrode when struck by beam halo ions.

The current to clearing electrode-c (between the third and fourth quadrupole magnets) is also strongly affected by the suppressor electrode, decreasing by about a factor of two when the suppressor is on at $-10 \mathrm{kV}$, Fig. 14(b). This demonstrates that electrons drift through the fourth quadrupole magnet to reach clearing electrode-c. However, the currents to clearing electrodes-a and -b are unaffected by suppressor bias, Fig. 14(c,d). This demonstrates that clearing electrode-c is performing as intended, it removes essentially all electrons from the drift region between magnets 3 and 4 [9].

To determine the source of the finite clearing electrode currents, when the suppressor is biased to $-10 \mathrm{kV}$ to prevent end-wall emission from reaching the magnets, we varied the pressure by reducing pumping speed and injecting gas. The results are shown in Fig. 15, where we see that the clearing current at base pressure is nearly identical to that extrapolated to zero pressure. This shows that the source of electrons is not ionization of gas. By elimination, the electrons must come from the beam tubes [12].

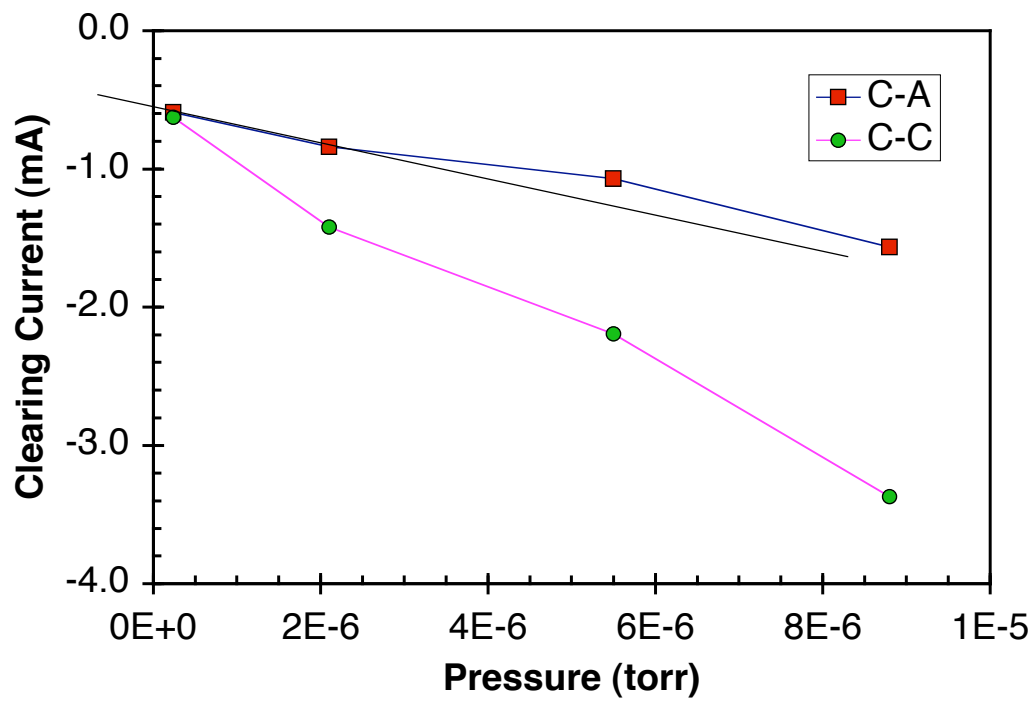

Figure 15. The current to clearing electrodes A and C (see Fig. 4 for location) is plotted versus the pressure in the magnets. Both extrapolate to $\sim 0.5 \mathrm{~mA}$ at zero pressure. 
Electrons can arise from three sources, as mentioned: ionization of gas, beam-tube emission when impacted by ions, electrons or photons, and end-wall emission. End-wall emission is not a problem; we have shown that electrostatic suppression can eliminate it. When we bias the suppressor electrode to $-10 \mathrm{kV}$, we eliminate electrons from the end wall, but we still have a small current from other sources to the clearing electrodes between magnets.

We can also prevent electrons off the end-wall from reaching clearing electrodes A or B by biasing Clearing- $\mathrm{C}$ to $\geq 4 \mathrm{kV}$, as shown in Fig. 16. We have made other measurements and done simulations to understand the source of the remaining electrons to clearing electrodes $\mathrm{A}$ and $\mathrm{B}$.

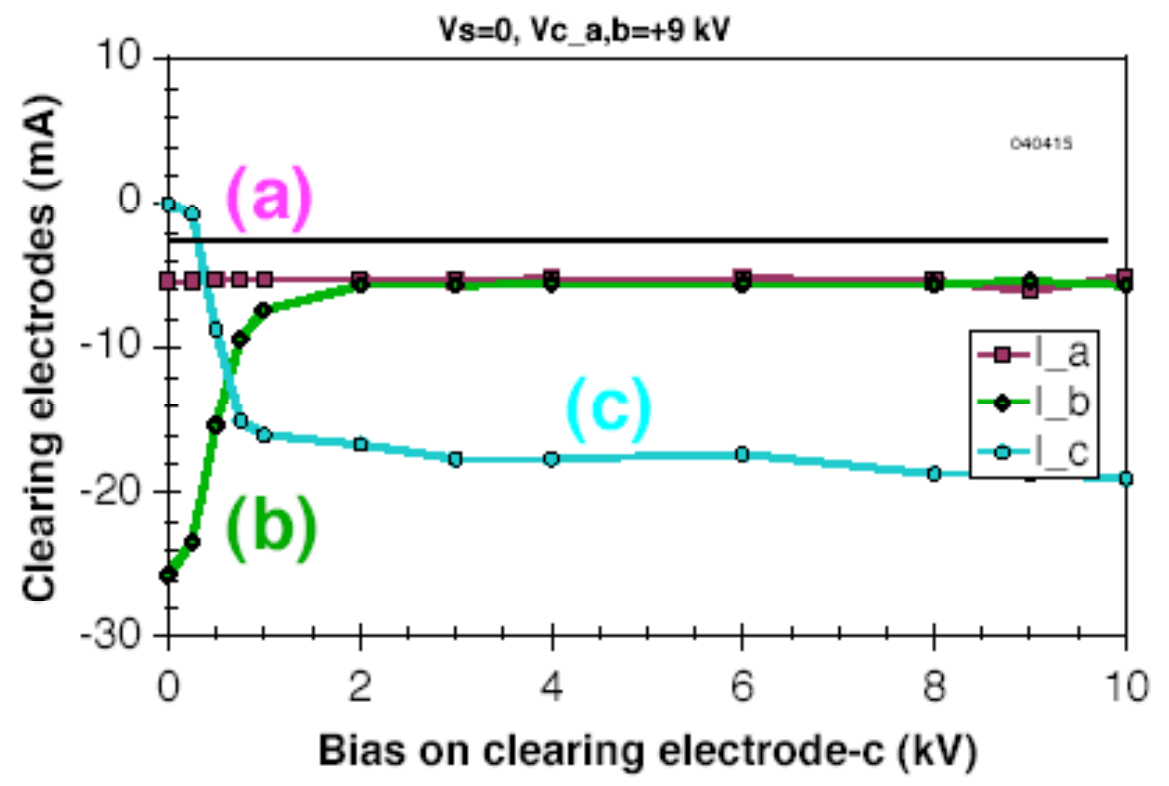

Fig. 16. The currents to Clearing electrodes A, B, and C are plotted versus the bias voltage on clearing electrode- $\mathrm{C}$, with the suppressor bias off. When $\mathrm{C}$ is biased to voltages greater than $+4 \mathrm{kV}$, it collects all the electrons from the end wall, preventing them from reaching electrodes A or B. However, these electrodes still draw a current of $\sim 3 \mathrm{~mA}$.

\section{End wall emission}

In the last section, we showed that the suppressor electrode is effective at blocking electrons emitted by the end wall from reaching the magnets, Fig. 14. This enables us to perform experiments with little or no contamination from end-wall emitted electrons. However, if we turn off the bias on the suppressor to admit these electrons, we have observed interesting phenomena, including oscillations in the electron population drifting through magnet 4 , and significant distortions of the ion-beam phase space. We are continuing efforts to understand these to determine whether they are of only academic interest, or whether we should to be concerned that they could occur in long accelerators even without any electrons from an end wall. 
Early observations with unsuppressed end-wall emission, and one clearing electrode biased for each shot, showed a delay in electrons reaching clearing electrodes that increased with the distance from the end wall, Fig. 17. Simulations produced remarkable agreement with the time of arrival. This indicates that the beam potential is being accurately simulated because the electron velocity through a quadrupole magnet is the sum of E x B, grad-B, and curvature drift velocities: the E x B velocity scales linearly with the electric field which is proportional to the beam potential, grad-B and curvature drift velocities are proportional to the electron energy perpendicular and parallel respectively to the magnetic field - these energies will also vary linearly with the beam potential, because an electron created anywhere, except at the peak beam potential (i.e., near the beam axis), will be accelerated to an energy of some fraction of the beam potential.

We also note that the magnitude of the simulated current agrees very well for electrode $\mathrm{C}$, but less well for electrodes A and B, for reasons discussed in Section 3. The agreement for clearing electrode $\mathrm{C}$ is particularly intriguing as both the experiment and the simulation show significant oscillations in the current, and they agree in the frequency and magnitude of the oscillations as well as the overall signal level.

These oscillations, as well as another plot from these simulations in the RZ plane, shown in Figs. 17 and 18, indicate an apparent instability in the fourth quadrupole magnet. We have continuing study of this phenomenon through simulation and experiments.

Electron cloud effects generally occur gradually, over many passes of a beam through an accelerator ring. However, we have demonstrated in both experiment and simulation that, when electron densities approach the beam density, electrons can significantly degrade beam properties in the short distance of 2 lattice periods (four quadrupole magnets) in a linac.

An example of the effect of switching the suppressor on and off is shown in Fig. 19. With the suppressor on to suppress electron emission from the end wall, we minimize electrons, yet the experiment still shows small kinks at the ends of the XX' phase space plots with a slight "Z" behavior. With the suppressor off to allow electron emission from the end wall to enter the quadrupole magnets, we see large kinks with a strong " $Z$ " distortion of phase space. Simulations using a semi-Gaussian beam with the suppressor on, resulting in no electrons in the beam, show a well-behaved ion beam with no Z-like kinks in the phase-space distribution. Simulations with the suppressor off allow electron densities to approach the beam density; this produces significant effects on the beam, qualitatively reproducing the dominant Z-phase space. Further details are available in Ref. [10].

Initial simulations without electrons used a semi-Gaussian distribution and showed little of the "hooking" or incipient "Z-ing" seen in the experiment even with the suppressor on, 

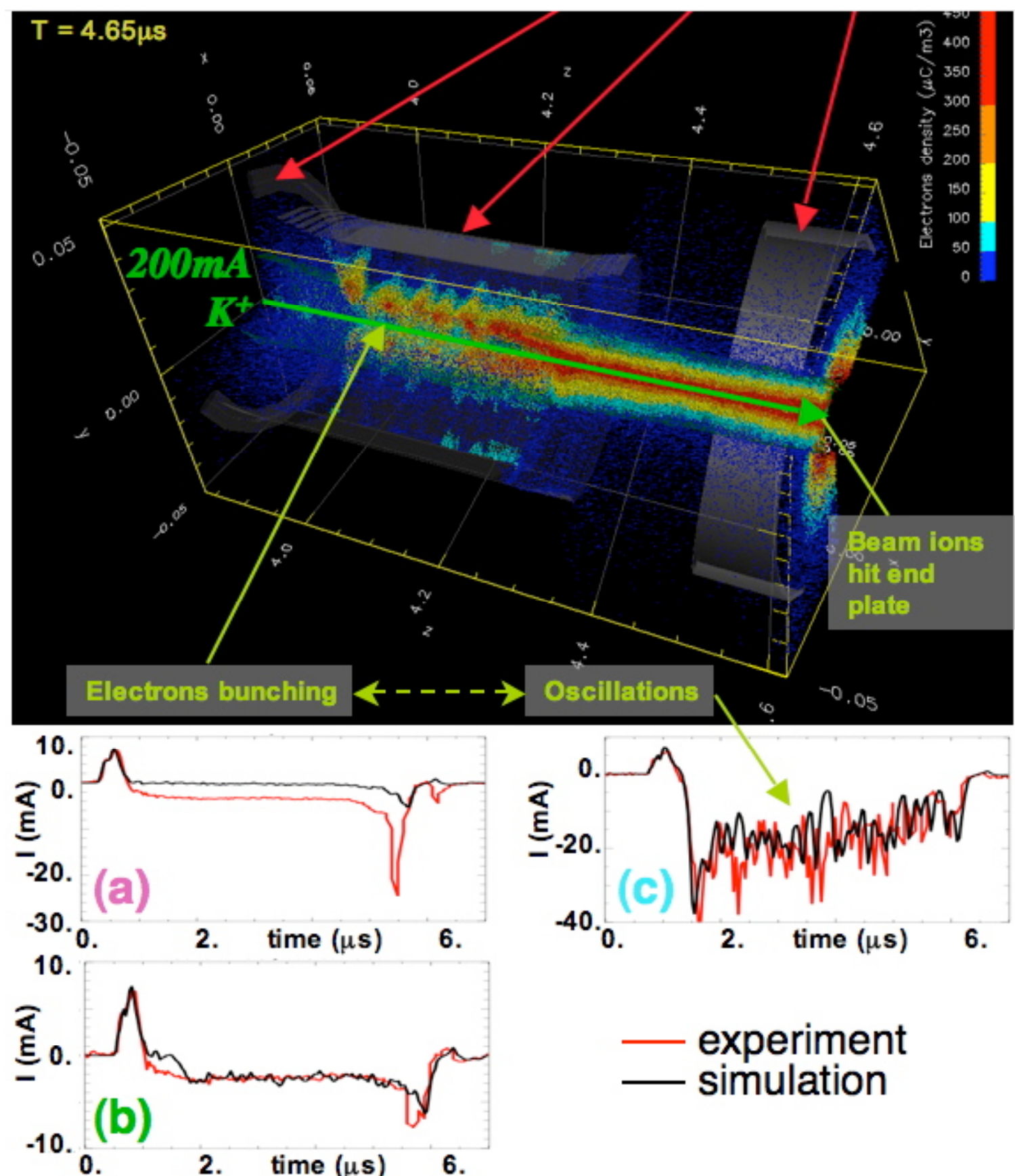

Figure 17. Study of electron-cloud buildup in HCX experiment; top panel: layout of experiment, with biased electrode locations denoted by lower case letters and magnetic quadrupoles labeled MA(i); middle panel: 3D snapshot of WARP simulation; lower panel: comparison of measured and simulated current waveforms as measured at electrodes. 


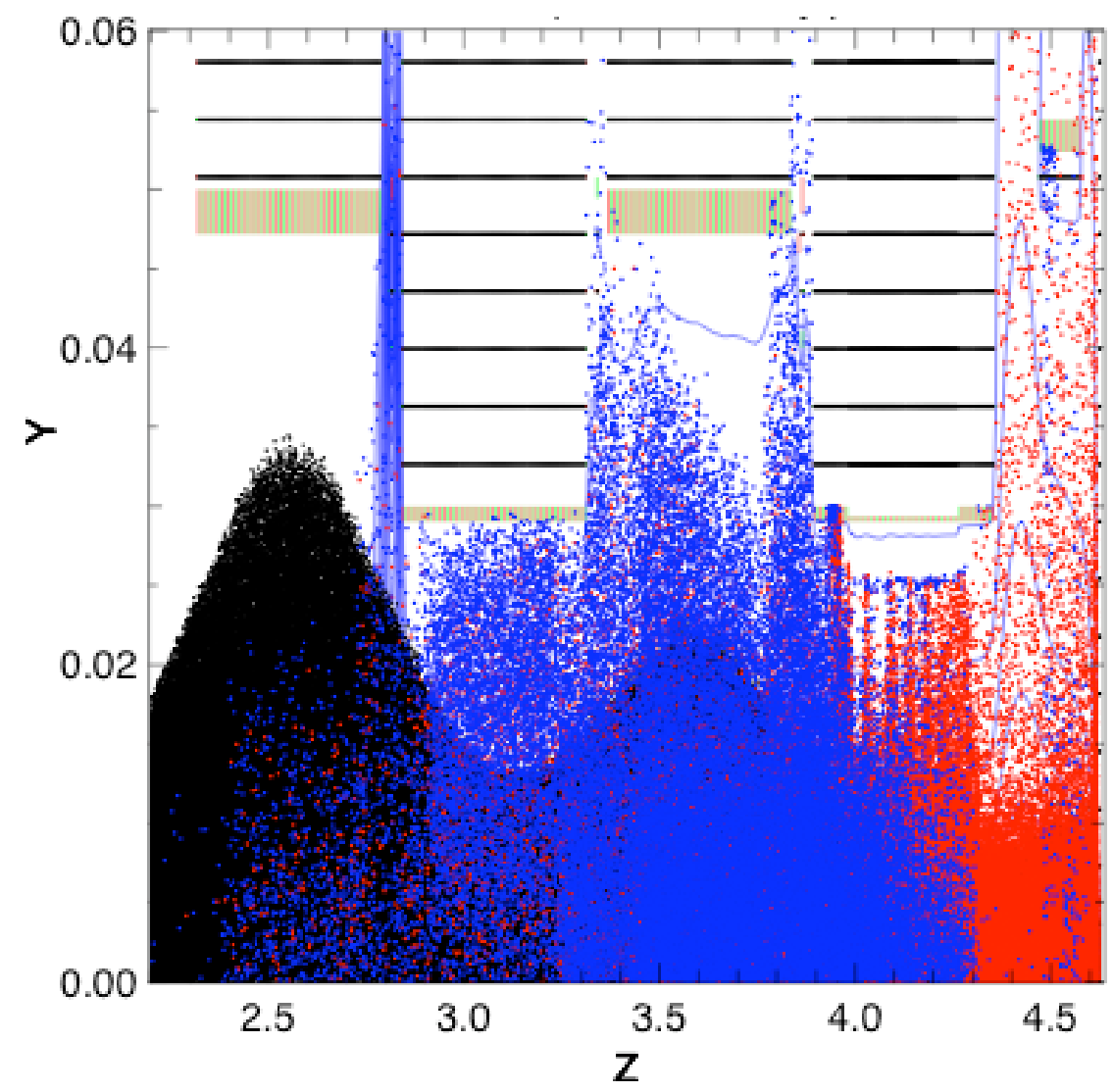

Figure 18. We show WARP simulation results for an emitting end wall. We show the ion beam (black), primary electrons (red) and secondary electrons (blue). The last color to be plotted obscures earlier colors. An oscillation is seen in magnet 4, from 3.9 to $4.3 \mathrm{~m}$.

as shown in Fig. 8. It was tempting to ascribe these effects to residual electrons, and perhaps part of the effect is due to electrons; however, using a tool developed in a student project, we recently "synthesized" [40] a beam distribution from optical diagnostics [41,42] at D2 (immediately preceding the quadrupole magnets), which, when used to initialize Warp PIC runs without electron effects, does recover much of the phase space distortion observed in the experiment, Fig. 20. This is being explored further, by checking with other magnet tune settings, and via a systematic set of simulations with a (high) phase advance, which mimics the experimental conditions.

These results emphasize the importance of developing self-consistent codes, and carefully benchmarking them against experiments under a variety of conditions, in order to gain confidence in the predictive capability of a code and to be confident that agreement with experiment is not merely fortuitous.

We have also applied the reconstructed beam to computing beam profiles in X-Y space. Scintillator measurements of the beam showed a somewhat-asymmetric approximately- 
diamond-shaped beam in Gap B (between magnets 2 and 3 in Fig. 1). Simulations with semi-Gaussian beams failed to reproduce these details in the beam shape. However, using the reconstructed beam profiles, the similarity of the simulated and measured beam shapes is striking, Fig. 21.

This agreement on shape is of more than academic interest. First, it provides reason to hope that future reconstructions will enable beam head scraping and halo scraping simulations to agree with experiment. Simulations should then replicate the measured clearing electrode currents to electrodes-A and B. Secondly, we are measuring the beam potential as a function of time with a retarding potential analyzer (RPA). This summer, a student project succeeded in computing the beam potential contours for the beam profile measured with the scintillator. These will aid in inferring beam potential profiles from experimental measurements of beam-potential-expelled ion energy distributions.

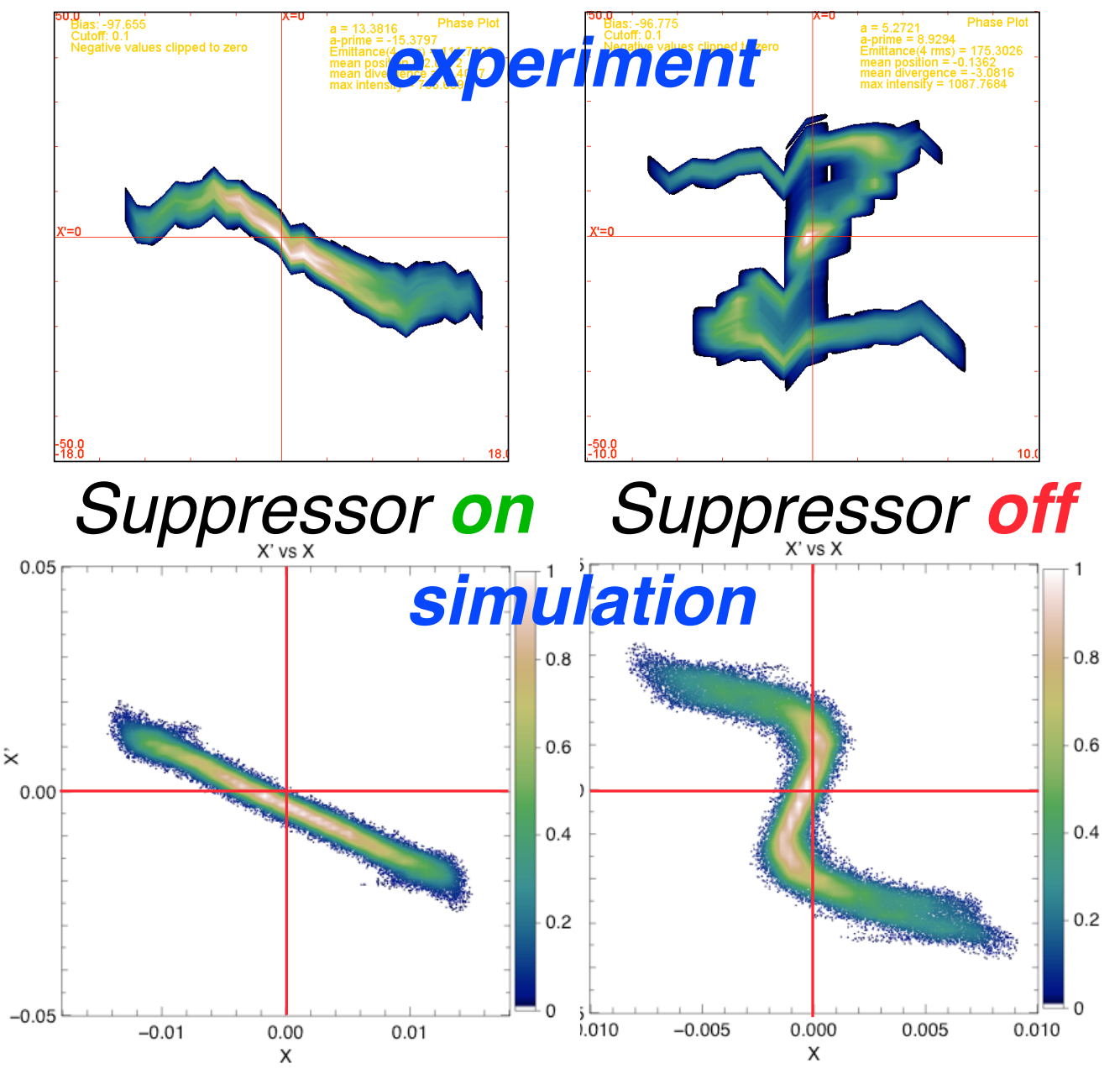

Figure 19. The experimental $X^{\prime} X$ phase space is measured with an optical slit scanner developed by F. Bieniosek. The WARP simulation demonstrates semi-quantitative agreement with the experiment using semi-Gaussian beams. 


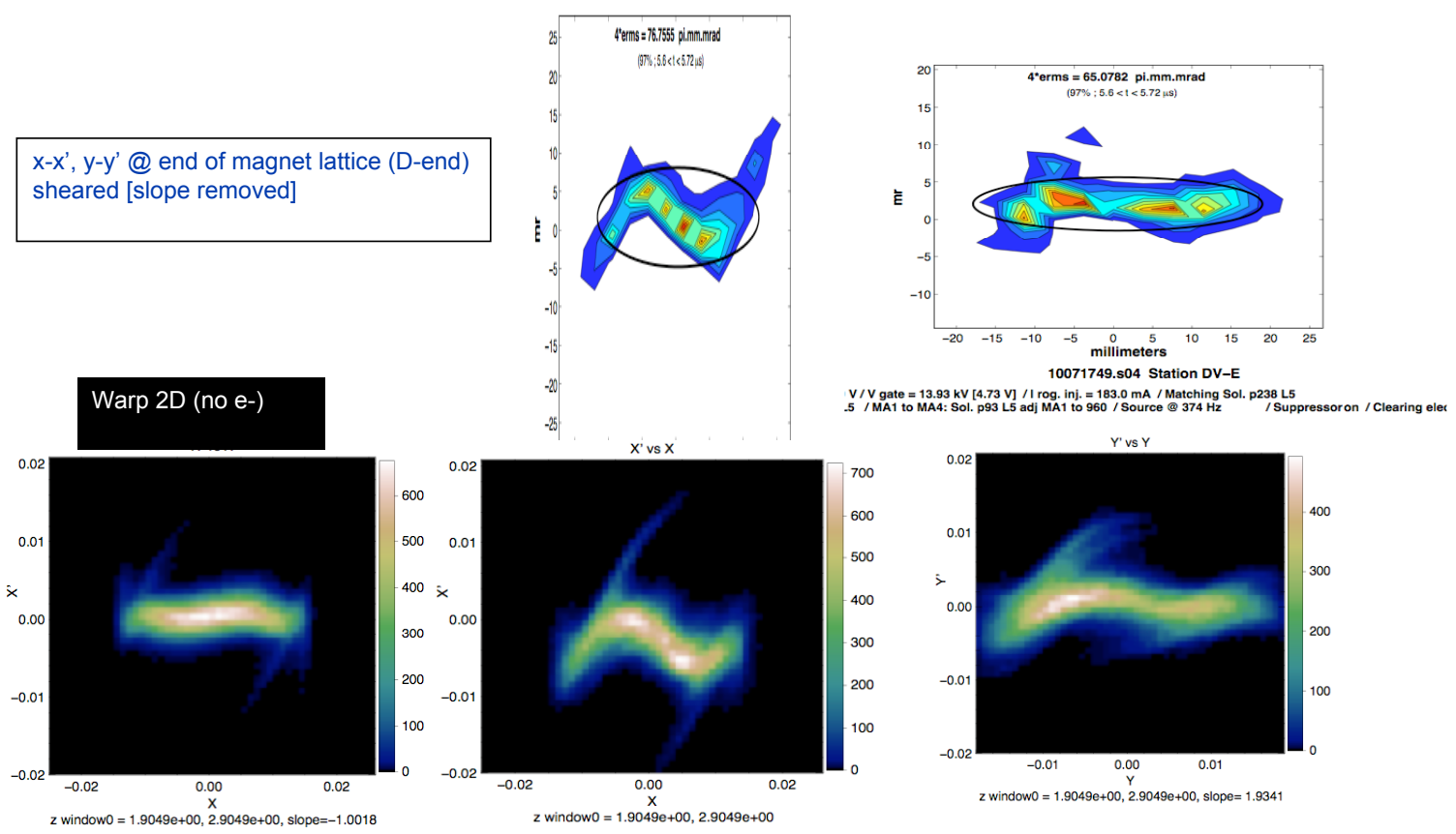

Figure 20. Simulation initialized with reconstructed 4D phase space from upstream optical diagnostic captures the observed distribution distortions downstream. The top center and right show the experimental $\mathrm{X}-\mathrm{X}^{\prime}$ and $\mathrm{Y}-\mathrm{Y}^{\prime}$ distributions. The corresponding WARP results are below, using the reconstructed phase space without electrons. The lower left shows the X-X' view of the WARP simulation with semi-Gaussian beam distribution.

\section{WARP (initialized with D2 data reconstruction)}

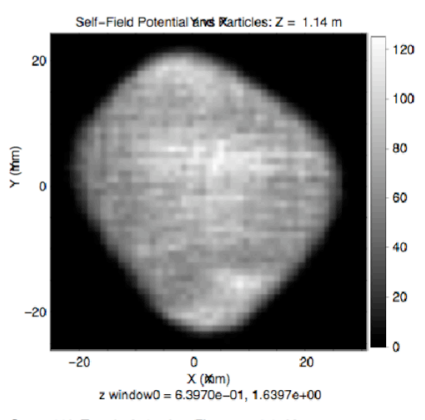

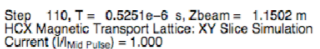

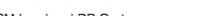

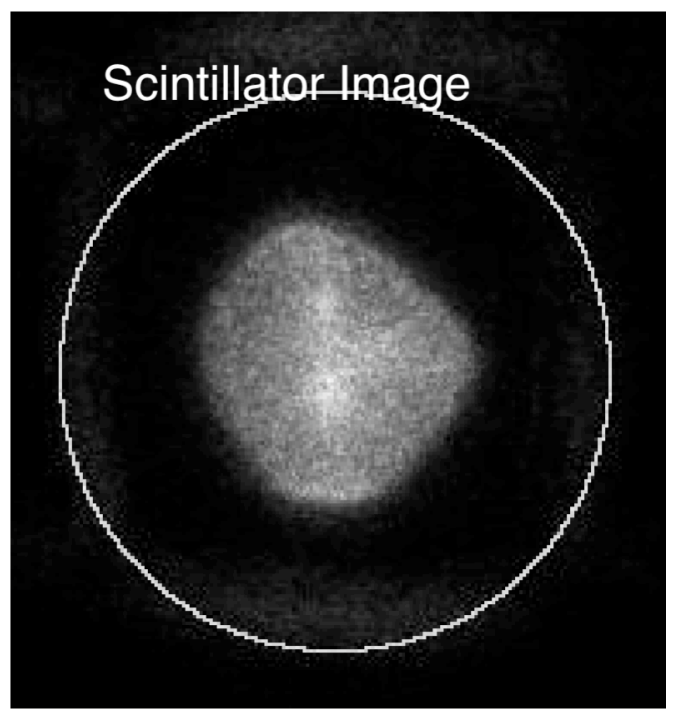

Fig. 21. Simulated (with reconstructed beam distribution) and measured beam profiles at gap-B. 


\section{EXIT PLAN}

We have made presentations to the DOE High Energy Physics Accelerator Office, as well as to the major operating and planned accelerator projects. These include the LHC Advanced Research Project (LARP), from which the Heavy-Ion Fusion Science Virtual National Laboratory (HIFS-VNL) has received partial FTE funding; the ILC for which we have joined in an LBNL proposal after discussions with both LLNL and LBNL groups that were interested in this work; Fermi-Lab where two of us presented a seminar in June, 2005 and engaged in discussions for a day - they were primarily concerned about electron cloud issues in the Proton Driver and are interested in using the WARP Code; Brookhaven where they have concerns about gas desorption in RHIC; and we have an ongoing discussion with GSI-Darmstadt that was awarded a $675 \mathrm{M}$ Euro project contingent on their upgrading the beam current by a factor of 1000 . We are encouraged by increased funding in the FY07 Budget for some of these projects that were threatened with shutdown a few months ago - funding for supporting activities is much more likely to be available now. We are also participating in a SCIDAC proposal. We are continuing in outreach efforts to attract more outside funding.

The success of this LDRD project has enabled the Heavy-Ion Fusion Science Virtual National Laboratory (HIFS-VNL) to continue E-Cloud work as their second activity, in addition to the High-Energy Density Physics that they are currently chartered to do. Continuing E-Cloud work has been endorsed (and praised) by the HIFS-VNL Program Advisory Committee as well as by the DOE Office of Fusion Energy Science.

\section{SUMMARY}

This project obtained outstanding results by several metrics: the initial goals were achieved during the 3 year LDRD period as discussed in the Abstract, we had 13 publications with 8 of them in refereed journals, our work was recognized by the accelerator and plasma physics communities by 8 invited papers and we have 5 additional invitations for invited papers at upcoming conferences, we attracted collaborators who had SBIR funding, and we are collaborating with scientists at CERN and GSI Darmstadt on an upcoming publication.

We include a Bibliography of our LDRD funded work, plus that of our collaborators during this period, and a separate list of References. Numbers in the Bibliography correspond to those of the References.

\section{Bibliography (03-ERD-008 LDRD-related publications)}

3. R. H. Cohen, A. Friedman, S. Lund, A. W. Molvik, ,E. P. Lee, T. Azevedo, J.-L. Vay, P. Stoltz, and S. Veitzer, "Electron-Cloud Simulation and Theory for HighCurrent Heavy-Ion Beams," Physical Review Special Topics - Accelerators and Beams 7, 124201-1 - 124201-20 (2004).

4. A. W. Molvik ${ }^{1}$, J.J. Barnard, E. M. Bringa, D. A. Callahan, C. M. Celata, R.H. Cohen, A. Friedman, M.A. Furman, J. W. Kwan, B. G. Logan, W. R. Meier, A. 
Sakumi, P.A. Seidl, W. Stoeffl, S. S. Yu, "HIF (Heavy Ion Fusion) Gas Desorption Issues", Invited paper at ICFA Workshop on Beam-Induced Pressure Rise in Rings, Brookhaven National Laboratory, Dec. 9-12, 2003.

5. A. W. Molvik, M. Kireeff Covo, F. M. Bieniosek, L. Prost, P. A. Seidl, D. Baca, A. Coorey, and A. Sakumi, "Gas desorption and electron emission from $1 \mathrm{MeV}$ potassium ion bombardment of stainless steel," Physical Review Special Topics Accelerators and Beams 7, 093202 (2004).

6. R. H. Cohen, A. Friedman, S. Lund, A. W. Molvik, ,E. P. Lee, T. Azevedo, J.-L. Vay, P. Stoltz, and S. Veitzer, "Modeling Electron-Cloud Effects in Heavy-Ion Accelerators," Invited Paper, Ecloud04 ICFA Workshop, 4/19-23/04, Napa, CA (2004). Available at http://mafurman.lbl.gov/ECLOUD04_proceedings/, UCRL PROC-206744.

7. A.W. Molvik, F. M. Bieniosek, J.J. Barnard, D. A. Callahan, R. H. Cohen, A. Friedman, M. Kireeff Covo, J. W. Kwan, W. R. Meier, L. Prost, A. Sakumi, P.A. Seidl, S. S. Yu. "Experimental Studies of Electron and Gas Sources in a Heavy-Ion Beam,” Invited Paper, Ecloud04 ICFA Workshop, 4/19-23/04, Napa, CA, (2004). Available at http://mafurman.lbl.gov/ECLOUD04_proceedings/, UCRL-PRES203920 and UCRL-CONF-207208.

8. R. H. Cohen, A. Friedman, S. M. Lund, A. W. Molvik, ,E. P. Lee, T. Azevedo, J.-L. Vay, P. Stoltz, and S. Veitzer, "Simulating Electron-Cloud Effects in Heavy-Ion Beams," Invited Paper, HIF-2004 International Heavy-Ion Inertial Fusion Symposium, Princeton University, Princeton, NJ, June 7-11, 2004, Nuc. Instrum,. And Methods A, 544, 210-215 (2005).

9. A.W. Molvik, P. A. Seidl, F. M. Bieniosek, R. H. Cohen, M. Kireeff Covo, L. Prost, "Experimental Studies of Electrons in a Heavy-Ion Beam", Invited Paper HIF-2004 International Heavy-Ion Inertial Fusion Symposium, Princeton University, Princeton, NJ, June 7-11, 2004, Nuc. Instrum,. And Methods A, 544, 194-201 (2005).

10. R. H. Cohen, A. Friedman, M. Kireeff Covo, S. M. Lund, and A. W. Molvik, F. M. Bieniosek, P. A. Seidl, and J.- L. Vay, P. Stoltz, and S. Veitzer, "Simulating electron clouds in heavy-ion accelerators," Invited paper at APS-DPP, Savannah, Nov. 2004, Phys. Plasmas 12, 056708 (2005).

11. J.-L. Vay, M. A. Furman, P. A. Seidl, LBNL, R. H. Cohen, A. Friedman, D. P. Grote, M. Kireeff Covo, A. W. Molvik, LLNL, P. H. Stoltz, S. Veitzer, Tech-X Corp., J. Verboncoeur, UC Berkeley, "Filling in the Roadmap for self-Consistent Electron Cloud and Gas Modeling," Invited paper at 2005 Particle Accelerator Conference, Knoxville, TN, May 16-20, 2005.

12. A.W. Molvik, M. Kireeff Covo, A. Friedman, R. Cohen, S.M. Lund, J.J. Barnard, LLNL,; F. Bieniosek, P. Seidl, D. Baca, J.-L. Vay, C.M. Celata, W.L. Waldron, LBNL, ; J.L. Vujic, Univ. California, Berkeley, "Experiments Studying Desorbed Gas and Electron Clouds in Ion Accelerators," Invited paper at 2005 Particle Accelerator Conference, Knoxville, TN, May 16-20, 2005.

14. P. H. Stoltz, M. A. Furman, J.-L. Vay, A. W. Molvik, and R. H. Cohen, "Numerical simulation of the generation of secondary electrons in the High Current Experiment," Physical Review Special Topics - Accelerators and Beams 6, 054701 (May, 2003). URL: http://link.aps.org/abstract/PRSTAB/v6/i5/e054701, 
15. P. Stoltz, S. Veitzer, R. Cohen, A. W. Molvik, and J.-L. Vay," Simulation of heavyion induced electron yield at grazing incidence," Physical Review Special Topics Accelerators and Beams 7, 103201-1 (2004).

16. Stoltz, P.H.; Veitzer, S.A.; Cohen, R.; Molvik, A.; Vay J-L., "Electron Effects Due to Grazing Collisions Between Heavy Ions and Walls," Nuclear Instruments and Methods in Physics Research A 544, 502-505 (2005).

17. A. W. Molvik, et al., to be submitted to Phys. Rev. Lett.

18. M, Kireeff Covo, et al., to be submitted to Physical Review Special Topics Accelerators and Beams.

19. L. R. Prost, P. A. Seidl, F. M. Bieniosek, C. M. Celata, A. Faltens, D. Baca, E. Henestroza, J. W. Kwan, M. Leitner, W. L. Waldron, R. Cohen, A. Friedman, D. Grote, S. M. Lund, A. W. Molvik, and E. Morse, "High current transport experiment for heavy ion inertial fusion," Physical Review Special Topics Accelerators and Beams 8, 020101 (2005).

31. B. G. Logan, F. M. Bieniosek, C. M. Celata, et al., "Overview of US heavy ion fusion research," Nuclear Fusion 45, 131-137 (2005).

41. F. M. Bieniosek, S. Eylon, A. Faltens, A. Friedman, J. W. Kwan, M. A. Leitner, A. W. Molvik, L. Prost, P. K. Roy, P. A. Seidl, G. Westenskow, "Diagnostics for intense heavy-ion beams in the HIF-VNL," Nuclear Instruments and Methods in Physics Research A 544, 268-276 (2005).

42. F. M. Bieniosek, L Prost, W. Ghiorso, "Beam imaging diagnostics for heavy ion beam fusion experiments, "Proc. of Particle Accelerator Conference, Portland, OR, May 12-16, 2003, p. 2524.

\section{REFERENCES}

1. M. T. F. Pivi and M. A. Furman, Phys. Rev. ST Accelerators and Beams 6, 034201 (2003).

2. D. P. Grote, A. Friedman, I. Haber, Fus. Eng. \& Des. 32-33, 193 (1996), available at http://hif.lbl.gov/theory/WARP.summary.html

3. R. H. Cohen, A. Friedman, S. Lund, A. W. Molvik, ,E. P. Lee, T. Azevedo, J.-L. Vay, P. Stoltz, and S. Veitzer, "Electron-Cloud Simulation and Theory for HighCurrent Heavy-Ion Beams," Physical Review Special Topics - Accelerators and Beams 7, 124201-1 - 124201-20 (2004).

4. A. W. Molvik ${ }^{1}$, J.J. Barnard, E. M. Bringa, D. A. Callahan, C. M. Celata, R.H. Cohen, A. Friedman, M.A. Furman, J. W. Kwan, B. G. Logan, W. R. Meier, A. Sakumi, P.A. Seidl, W. Stoeffl, S. S. Yu, "HIF (Heavy Ion Fusion) Gas Desorption Issues", Invited paper at ICFA Workshop on Beam-Induced Pressure Rise in Rings, Brookhaven National Laboratory, Dec. 9-12, 2003.

5. A. W. Molvik, M. Kireeff Covo, F. M. Bieniosek, L. Prost, P. A. Seidl, D. Baca, A. Coorey, and A. Sakumi, "Gas desorption and electron emission from $1 \mathrm{MeV}$ potassium ion bombardment of stainless steel," Physical Review Special Topics Accelerators and Beams 7, 093202 (2004).

6. R. H. Cohen, A. Friedman, S. Lund, A. W. Molvik, ,E. P. Lee, T. Azevedo, J.-L. Vay, P. Stoltz, and S. Veitzer, "Modeling Electron-Cloud Effects in Heavy-Ion 
Accelerators," Invited Paper, Ecloud04 ICFA Workshop, 4/19-23/04, Napa, CA (2004). Available at http://mafurman.lbl.gov/ECLOUD04_proceedings/, UCRL PROC-206744.

7. A.W. Molvik, F. M. Bieniosek, J.J. Barnard, D. A. Callahan, R. H. Cohen, A. Friedman, M. Kireeff Covo, J. W. Kwan, W. R. Meier, L. Prost, A. Sakumi, P.A. Seidl, S. S. Yu. "Experimental Studies of Electron and Gas Sources in a Heavy-Ion Beam,” Invited Paper, Ecloud04 ICFA Workshop, 4/19-23/04, Napa, CA, (2004). Available at http://mafurman.lbl.gov/ECLOUD04_proceedings/, UCRL-PRES203920 and UCRL-CONF-207208.

8. R. H. Cohen, A. Friedman, S. M. Lund, A. W. Molvik, ,E. P. Lee, T. Azevedo, J.-L. Vay, P. Stoltz, and S. Veitzer, "Simulating Electron-Cloud Effects in Heavy-Ion Beams," Invited Paper, HIF-2004 International Heavy-Ion Inertial Fusion Symposium, Princeton University, Princeton, NJ, June 7-11, 2004, Nuc. Instrum,. And Methods A, 544, 210-215 (2005).

9. A.W. Molvik, P. A. Seidl, F. M. Bieniosek, R. H. Cohen, M. Kireeff Covo, L. Prost, "Experimental Studies of Electrons in a Heavy-Ion Beam", Invited Paper HIF-2004 International Heavy-Ion Inertial Fusion Symposium, Princeton University, Princeton, NJ, June 7-11, 2004, Nuc. Instrum,. And Methods A, 544, 194-201 (2005).

10. R. H. Cohen, A. Friedman, M. Kireeff Covo, S. M. Lund, and A. W. Molvik, F. M. Bieniosek, P. A. Seidl, and J.- L. Vay, P. Stoltz, and S. Veitzer, "Simulating electron clouds in heavy-ion accelerators," Invited paper at APS-DPP, Savannah, Nov. 2004, Phys. Plasmas 12, 056708 (2005).

11. J.-L. Vay, M. A. Furman, P. A. Seidl, LBNL, R. H. Cohen, A. Friedman, D. P. Grote, M. Kireeff Covo, A. W. Molvik, LLNL, P. H. Stoltz, S. Veitzer, Tech-X Corp., J. Verboncoeur, UC Berkeley, "Filling in the Roadmap for self-Consistent Electron Cloud and Gas Modeling," Invited paper at 2005 Particle Accelerator Conference, Knoxville, TN, May 16-20, 2005.

12. A.W. Molvik, M. Kireeff Covo, A. Friedman, R. Cohen, S.M. Lund, J.J. Barnard, LLNL,; F. Bieniosek, P. Seidl, D. Baca, J.-L. Vay, C.M. Celata, W.L. Waldron, LBNL, ; J.L. Vujic, Univ. California, Berkeley, "Experiments Studying Desorbed Gas and Electron Clouds in Ion Accelerators," Invited paper at 2005 Particle Accelerator Conference, Knoxville, TN, May 16-20, 2005.

13. M. Kireeff Covo**, A. Molvik, A. Friedman, G. Westenskow, J.J. Barnard, R. Cohen, S.M. Lund, and D. Grote, LLNL, P. Seidl, J.W. Kwan, D. Baca, F. Bieniosek, C.M. Celata, J.-L. Vay, LBNL, J.L. Vujic, UCB, "BEAM ENERGY SCALING OF ION-INDUCED ELECTRON YIELD FROM K+ IONS IMPACT ON STAINLESS STEEL SURFACES”, presented at 2005 Particle Accelerator Conference, Knoxville, TN, May 16-20, 2005.

14. P. H. Stoltz, M. A. Furman, J.-L. Vay, A. W. Molvik, and R. H. Cohen, "Numerical simulation of the generation of secondary electrons in the High Current Experiment," Physical Review Special Topics - Accelerators and Beams 6, 054701 (May, 2003). URL: http://link.aps.org/abstract/PRSTAB/v6/i5/e054701,

15. P. Stoltz, S. Veitzer, R. Cohen, A. W. Molvik, and J.-L. Vay," Simulation of heavyion induced electron yield at grazing incidence," Physical Review Special Topics Accelerators and Beams 7, 103201-1 (2004). 
16. Stoltz, P.H.; Veitzer, S.A.; Cohen, R.; Molvik, A.; Vay J-L., "Electron Effects Due to Grazing Collisions Between Heavy Ions and Walls," Nuclear Instruments and Methods in Physics Research A 544, 502-505 (2005).

17. A. W. Molvik, et al., to be submitted to Phys. Rev. Lett.

18. M, Kireeff Covo, et al., to be submitted to Physical Review Special Topics Accelerators and Beams.

19. L. R. Prost, P. A. Seidl, F. M. Bieniosek, C. M. Celata, A. Faltens, D. Baca, E. Henestroza, J. W. Kwan, M. Leitner, W. L. Waldron, R. Cohen, A. Friedman, D. Grote, S. M. Lund, A. W. Molvik, and E. Morse, "High current transport experiment for heavy ion inertial fusion," Physical Review Special Topics - Accelerators and Beams 8, 020101 (2005).

20. S. Y. Zhang, "ICFA Workshop on Beam Induced Pressure Rise in Rings," http://www.c-ad.bnl.gov/icfa (2003).

21. E. Mahner, J. Hansen, J.-M. Laurent, and N. Madsen, Phys. Rev. ST AB 6, 013201 (2003).

22. E. Mahner et al., Phys. Rev. ST AB 7, 103202 (2004).

23. J. F. Ziegler, http://www.srim.org/.

24. T. Schenkel, private communication (2003).

25. R. E. Johnson, Rev. Mod. Phys. 68, 305 (1996).

26. http://www.gsi.de/documents/DOC-2004-Nov-130-1.pdf [very general].

27. J. W. Kwan et al., Nucl. Instrum. Methods A 544, 134 (2005).

28. R. Davidson et al., "Frontiers in High Energy Density Physics: The X-Games of Contemporary Science," The National Academies Press (2003).

29. N. A. Tahir et al., Phys. Rev. Lett. 95, 035001 (2005).

30. P. Roy et al, Phys. Rev. Lett. 95, 234801 (2005).

31. B. G. Logan, F. M. Bieniosek, C. M. Celata, et al., "Overview of US heavy ion fusion research," Nuclear Fusion 45, 131-137 (2005).

32. S. S. Yu et al., Fusion Sci. and Technol. 44, 266 (2003).

33. G. F. Matthews, J. Nucl. Mater. 337-339, 1 (2005).

34. W. W. Heidbrink, G. Sadler, Nucl. Fusion 34, 535 (1994).

35. M. Kress, A. G. G. M. Tielens, Meteoritics and Planetary Sciences 36, 75, (2001).

36. G. J. White et al., Astron. Astrophys. 407, 589 (2003).

37. P. Hakansson, and B. U. R. Sundqvist, Vacuum 39, 397 (1989).

38. W. L. Brown et al., Phys. Rev. Lett. 45, 1632 (1980).

39. M. Kireeff Covo et al., to be submitted to Phys. Rev. ST AB.

40. A. Friedman, D. P. Grote, C. M. Celata, J. W. Staples, Laser and Particle Beams 21, 17 (2003).

41. F. M. Bieniosek, S. Eylon, A. Faltens, A. Friedman, J. W. Kwan, M. A. Leitner, A. W. Molvik, L. Prost, P. K. Roy, P. A. Seidl, G. Westenskow, "Diagnostics for intense heavy-ion beams in the HIF-VNL," Nuclear Instruments and Methods in Physics Research A 544, 268-276 (2005).

42. F. M. Bieniosek, L Prost, W. Ghiorso, "Beam imaging diagnostics for heavy ion beam fusion experiments, "Proc. of Particle Accelerator Conference, Portland, OR, May 12-16, 2003, p. 2524. 